\title{
Gentrification and Neighborhood Housing Cycles: Will America's Future Downtowns Be Rich?
}

\author{
Jan K. Brueckner \\ Department of Economics \\ University of California, Irvine \\ 3151 Social Science Plaza \\ Irvine, CA 92697 \\ Phone: (949) 824-0083 ; Fax: (949) 824-2182 \\ Email: jkbrueck@uci.edu \\ Home Page: http://www.socsci.uci.edu/ jkbrueck/ \\ and \\ Stuart S. Rosenthal \\ Department of Economics \\ 426 Eggers Hall \\ Syracuse University \\ Syracuse, NY 13244-1020 \\ Phone: (315) 443-3809; Fax: (315) 443-1081 \\ Email: ssrosent@maxwell.syr.edu \\ Home Page: http://faculty.maxwell.syr.edu/ROSENTHAL/
}

September 30, 2005

Funding for this project from the John D. and Catherine T. MacArthur Foundation, the Ford Foundation, and the Syracuse University Center for Policy Research is gratefully acknowledged. We thank Dan Black, Ken Small, and seminar participants at the University of Toronto for helpful comments. Excellent research assistance has been provided by Yong Chen and Michael Eriksen. Any shortcomings in the paper are ours alone. 


\begin{abstract}
This paper identifies a new factor, the age of the housing stock, that affects where high- and lowincome neighborhoods are located in U.S. cities. High-income households, driven by a high demand for housing services, will tend to locate in areas of the city where the housing stock is relatively young. Because cities develop and redevelop from the center outward over time, the location of these neighborhoods varies over the city's history. The model predicts a suburban location for the rich in an initial period, when young dwellings are found only in the suburbs, while predicting eventual gentrification once central redevelopment creates a young downtown housing stock. Empirical work indicates that if the influence of spatial variation in dwelling ages were eliminated, longstanding central city/suburban disparities in neighborhood economic status would be reduced by up to 50 percent. Model estimates further predict that between 2000 and 2020, central-city/suburban differences in economic status will widen somewhat in smaller cities but narrow sharply in the largest American cities as they become more gentrified.
\end{abstract}




\section{Introduction}

In the 1980 s, property values in parts of Harlem had fallen to nearly zero, with entire neighborhoods occupied by the poorest of the poor. Twenty years later, former President Bill Clinton established his office in Harlem amid a run-up in real estate values that saw some of those same properties selling for over one million dollars. Harlem's meteoric rise in economic status reflects the phenomenon of gentrification, under which previously poor central-city neighborhoods are revitalized by the in-migration of well-to-do households. While gentrification elicits different evaluations, being viewed as harmful by advocates of the displaced poor ${ }^{1}$ and desirable by its beneficiaries, the phenomenon has generated intense interest among policymakers, the press, and other observers.

Several questions about the gentrification process need answers. Is gentrification just a curiosity that affects a handful of neighborhoods and makes good material for newspaper feature stories? Or does the gentrification phenomenon reflect deep-seated forces that could substantially alter current location patterns in U.S. cities? If the latter view is correct, can the future course of gentrification be predicted by economic models that take account of the dynamic nature of the process? Such predictions are crucial for local policymakers and real-estate developers who must plan for the future despite their limited ability to predict the city's evolution (see Rosenthal (2005), for example).

This paper develops and tests a new model of the gentrification process, providing fresh insights into how high- and low-income households locate within a city and how their locations evolve over time. Our starting point is the standard urban model developed by Alonso (1964),

\footnotetext{
${ }^{1}$ See, for example, USA Today (July 31, 2001, page 1), "I'm home: Clinton opens Harlem Office," by Charisse Jones.
} 
Mills (1967) and Muth (1969). That model has been largely successful in explaining the spatial patterns of land-use and real estate prices in cities. However, the model has met with less success in predicting the location patterns of different income groups. Under the U.S. pattern, higher-income households tend to live in the suburbs. Among the largest cities, for example, central city average income is 40 percent below that in the suburbs, as will be shown later. However, gentrification can also generate rich neighborhoods close to the city center, complicating the location picture. In addition, in foreign cities, the U.S. pattern can be completely reversed, with the center occupied by the rich and the poor living in the suburbs (a notable example is Paris).

Within the standard model, the location of high-income households reflects the tension between two opposing forces: a housing-based pull toward the suburbs, where a high demand for housing can be satisfied at a low price per square foot, and a time-cost-based pull toward the center, where short commutes allow high-income households to save valuable time. Over the years, the U.S. location pattern has often been rationalized by viewing the housing-based force as dominant. However, Wheaton (1977) presented early empirical evidence showing that the two forces are approximately equal in size, implying an indeterminate pattern of location by income. Using newer evidence, Glaeser, Kahn, and Rappaport (2001) argue that the housingbased force is far weaker than the time-cost force, which would imply a central location for highincome households, contrary to the general U.S. pattern. Given such findings, a viable explanation for the strong (and often opposing) location patterns seen in U.S. and foreign cities must therefore be sought outside the basic urban model.

Several such explanations have been proposed in the literature. Brueckner, Thisse and Zenou (1999) argue that natural and historical amenities in the city center (an attractive river or 
beachfront; beautiful buildings, monuments, and parks inherited from the past) may attract the rich more strongly than the poor, leading to a Paris-style location pattern (see also Kern (1981)). ${ }^{2}$ LeRoy and Sonstelie (1983) instead argue that transport mode choice may provide the key to location patterns. They show that when a new, fast transport mode (the streetcar, or more recently, the automobile) is introduced and adopted only by the rich, the resulting weakening of the time-cost force for that group may cause them to abandon their initial central location and move to the suburbs, a reversal consistent with the current U.S. pattern. Glaeser, Kahn and Rappaport (2001) offer a related mode-based argument, pointing out that, because central cities have the high population densities required for convenient, frequent public transit service, they naturally attract a poor population, which must rely on this transit mode. Finally, various authors have advanced a fiscal explanation for location patterns, arguing that homogeneous suburban communities allow high-income households to escape redistributive central city taxation while improving the quality of public goods (see, for example, Nechyba and Walsh (2004)). ${ }^{3}$

Each of these arguments helps to explain the relative locations of high- and low-income households. But, being mostly based on static models, none of the arguments allows for neighborhood evolution over time and related implications for household location. This paper fills that gap by developing a dynamic model where the age of dwellings plays a central role in determining location patterns. The model portrays a city that grows outward from the center over time, with dwellings in each location torn down and replaced at the end of a fixed lifespan. Under this growth process, new dwellings are always found at the city's edge, but they will also be present at interior locations when enough time has passed for redevelopment to occur.

\footnotetext{
${ }^{2}$ Vancouver, British Columbia shares some of the features of Paris, with high-income families clustered around a very scenic downtown and lower-income families occupying more distant suburbs. A similar pattern occurs in La Paz, Bolivia, in which the downtown is located at a lower elevation (11,000 feet) with a more moderate climate, in contrast to the suburbs which extend up to a 14,000 foot plateau that suffers from a harsher climate.
} 
Consistent with filtering models (e.g. Sweeney (1974), Weicher and Thibodeau (1988), Rosenthal (2005)), housing is assumed to deteriorate with age, providing the impetus for redevelopment. ${ }^{4}$ Because the demand for housing services increases with income, high-income households are then drawn to areas of the city where dwellings are relatively young. If such dwellings are found only in the suburbs, then this force pulls the rich outward while the timecost-based force pulls them inward, setting up a tension analogous to that in the standard model. But when redevelopment brings new dwellings to central-city neighborhoods, then both forces work in tandem, pulling the rich toward the center. In this case, high-income households are likely to be found at both central and suburban locations, yielding the gentrification pattern seen in some U.S. cities. These insights are developed theoretically in section 2 of the paper.

The empirical analysis, which is contained in sections 3 and 4 of the paper, is designed to test the hypothesis that dwelling ages affect the pattern of location by income. The empirical work makes use of detailed census tract data for 331 individual MSAs. The initial regressions test for a positive correlation between income and distance like that seen in many previous studies. Using a neighborhood's relative income (a census tract's mean income divided by the MSA mean) to denote local economic status, this correlation is confirmed in the 2000 data.

The empirical work then turns to addressing the following key question: What pattern of location by income would emerge if the effect of spatial variation in dwelling ages were eliminated? The first step in the exercise is documenting the spatial dwelling-age pattern. Consistent with casual empiricism, the results show that average age falls as distance increases,

${ }^{3}$ Glaeser, Kahn, and Rappport (2001) also argue that central cities offer more generous social services for the poor.

${ }^{4}$ Additional theoretical papers on filtering include Braid (1986), and Brueckner (1980). Other empirical studies include Galster (1996), Coulson and Bond (1990), and Aaronson (1999). For a micro-level empirical analysis of the economics of housing redevelopment, see Rosenthal and Helsley (1994). See Glaeser and Gyourko (2005) for a discussion of how falling housing demand in declining cities can preclude redevelopment. 
with younger dwellings located in the suburbs. To address our key question, dwelling-age measures are then added as covariates in the relative-income regression, so that age is held constant in appraising the effect of distance on a census tract's economic status. The results of this exercise are striking. When relative income is taken to be a linear (and hence monotonic) function of distance, a tract's economic status tends to fall rather than rise as distance increases holding age fixed, suggesting that high-income households would tend to live near city centers were it not for old central housing stocks.

To allow for nonmonotonic distance effects, further regressions divide the city into narrow distance bands ( 1 or 2 miles in width), each represented by a dummy variable. Under this flexible specification, the impact of distance is no longer monotonic. But once dwelling age measures are added to the regression, the previous conclusion again emerges, although in more nuanced form. In particular, the results show that, if the influence of dwelling age were eliminated, the disparities in income between central city and suburban neighborhoods would be reduced by up to 50 percent, especially among the largest metropolitan areas. Moreover, the resulting spatial pattern of neighborhood economic status would be largely flat over broad areas of most cities.

We focus primarily on regressions that use dwelling age measures from 1980, rather than 2000 , to explain a tract's economic status in 2000. Using deeply lagged age measures helps to control for the possible endogenous character of dwelling ages. In addition, given this feature of the regression, the estimated model parameters can be used to forecast neighborhood economic status in 2020. This forecast, which is generated by substituting year-2000 age measures in place of 1980 measures in the regression equation, yields an answer to the question posed in the title of this paper. The results show that for smaller metropolitan areas, central city/suburban 
differences in economic status are predicted to widen slightly over the next several decades. But for the largest cities, central city/suburban differences in economic status are expected to narrow by up to 40 percent, equivalent to 20 percent of MSA mean income. Large as that effect might be, however, the central cities of the largest cities in the United States are still expected to be poor on average relative to suburban communities.

\section{Conceptual Model}

\subsection{City growth and the spatial pattern of dwelling ages}

As explained in the introduction, the goal of the model is to analyze the spatial pattern of location by income in a city that grows over time while experiencing cyclical redevelopment as dwellings age and are periodically replaced. For simplicity, the city is monocentric, with all employment located in the center, and the dwelling lifespan is set exogenously at $L$ years, where $L$ is a fixed constant independent of time and location. The effects of suburban employment centers and endogenous dwelling lifespans are discussed in sections 3 and 4.

The fixed lifespan assumption generates a distinctive spatial pattern of dwelling ages in a growing city. To understand the pattern, suppose that the city comes into being as a dimensionless point at time $t=0$ and expands outward as time progresses. Let $b(t)$ denote the distance to the edge of the city at time $t$, which satisfies $b^{\prime}(t)>0$. Then, let $T(x)$ denote the "development-date function," which gives the date at which land $x$ miles from the city center

(CBD) is first developed. This function satisfies $T(x) \equiv b^{-1}(x)$, with $T^{\prime}(x)>0$. Figure 1 graphs a representative $T(x)$ function, which is generated endogenously as part of a numerical simulation of the model, explained in detail below.

Consider a date $t$ in the city's evolution before any redevelopment has occurred, a value satisfying $t<L$. At this date, dwelling ages follow the spatial pattern shown in Figure 2a, with 
new dwellings located at the city's edge and age rising as $x$ decreases toward zero. Formally, Figure 2a is a graph of the function $a(x, t)$, which gives the age of dwellings at location $x$ at time $t$, with $a(x, t) \equiv t-T(x)$ when $t<L$. Thus, for $t<L$, dwelling age equals the current time minus the time at which development first occurred at the given location. Figure 2a, which is again based on the simulation, pertains to $t=63.7$ and reflects the assumption of a 75 -year dwelling lifespan $(L=75)$.

As time progresses beyond $L$, redevelopment occurs for dwellings near the CBD, which reach the end of their service lives and are replaced. These new dwellings then begin aging as time progresses, yielding the age pattern shown in Figure $2 \mathrm{~b}$ for $t=114.3$. At this date, the central part of the city has second-generation dwellings, while first-generation dwellings occupy its outer area. As time progresses further, spatial expansion of the city continues, and these first and second-generation dwellings are replaced by second and third generations, yielding the age pattern shown in Figure $2 \mathrm{c}$ at $t=187.5$. Thus, spatial growth along with the periodic redevelopment of dwellings generates a cyclical spatial pattern of dwelling ages.

To derive a general expression for the age pattern, let the function $\varphi(z)$ denote the "decimal part" of the number $z$ (i.e., the value generated by dropping $z$ 's integer part, keeping only the digits to the right of the decimal point). Then,

$$
a(x, t)=\varphi\left[\frac{t-T(x)}{L}\right] L .
$$

In (1), $[t-T(x)] / L$ gives the fractional number of dwelling lifespans that have passed since initial development at location $x$. The current dwelling has thus aged for a fraction of its lifespan equal to the decimal part of this expression, and multiplying by $L$ gives its age. 


\subsection{Additional elements of the model}

To develop the implications of dwelling age patterns like those shown in Figure 2 for the pattern of location by income, the additional elements of the model must be specified, as follows. City residents consume a nonhousing good, denoted $c$, and housing services, denoted $h$. The physical size of each dwelling is fixed for simplicity, but housing services depend negatively on the dwelling's age $a$, with $h=h(a)$, where $h^{\prime}(a)<0 .{ }^{5}$ Preferences are given by the well-behaved utility function $v(c, h)$.

City residents commute to jobs at the $\mathrm{CBD}$, and without loss of generality, time cost is assumed to be the only cost of commuting, with money cost suppressed. These time costs are generated in the simplest possible fashion by assuming that a minute of commute time reduces work time by a minute (leisure is thus fixed). Letting $y(t)$ denote "full" income at time $t$ (the amount that would be earned with no commute), disposable income at location $x$ is then $y(t)(1-$ $\tau x$ ), where $\tau$ gives the fraction of the full work period lost per mile of commuting, assumed constant over time for simplicity. Time- $t$ commuting cost from location $x$ is thus $y(t) \tau x$. Letting $R$ denote the rent per dwelling, the consumer's budget constraint is thus $c+R=y(t)(1-\tau x)$.

Substituting for $c$ in $v$, utility can be written $v[y(t)(1-\tau x)-R, h(a)]$, where the fixed $q$ argument of $h$ is suppressed. The consumer's bid-rent function, denoted $R(x, t)$, gives willingness-to-pay at time $t$ for the housing located at distance $x$, conditional on a fixed utility level $u(t)$. The bid-rent function is implicitly defined by the equation $v[y(t)(1-\tau x)-R, h(a(x, t))]$ $=u(t)$, and differentiating this equality to find its slope function yields

$$
\frac{\partial R}{\partial x}=-\tau y(t)+\frac{v_{h}}{v_{c}} h^{\prime}(a) \frac{\partial a}{\partial x} .
$$

\footnotetext{
${ }^{5}$ The effect of allowing dwelling square footage to be a choice variable is considered in supplemental analysis that is available on request.
} 
Note that since $a(x, t)$ is not differentiable at the jump points in Figure 2, (2) applies between these points.

Recalling that housing services decrease with age $\left(h^{\prime}(a)<0\right)$ and that age decreases with distance between the jumps in Figure $2(\partial a / \partial x<0)$, the second expression in (2) is positive between these jumps. Since the first expression in (2) is negative, the bid-rent function can either slope up or down over the distance ranges between the jumps. The intuitive explanation is that, while higher commuting costs make more distant locations less desirable, lower dwelling ages have the reverse effect. Since the implications of the model do not depend whether (2) is positive or negative, the slope is assumed to be positive.

\subsection{Patterns of location by income: preliminaries}

To investigate the pattern of location by income, let the city contain two income groups, denoted rich and poor, with incomes $y_{r}(t)$ and $y_{p}(t)<y_{r}(t)$. Each group has its own bid-rent function, with the slopes given by

$$
\begin{gathered}
\frac{\partial R_{r}}{\partial x}=-\tau y_{r}(t)+\left(\frac{v_{h}}{v_{c}}\right)_{r} h^{\prime}(a) \frac{\partial a}{\partial x} \\
\frac{\partial R_{p}}{\partial x}=-y_{p}(t)+\left(\frac{v_{h}}{v_{c}}\right)_{p} h^{\prime}(a) \frac{\partial a}{\partial x},
\end{gathered}
$$

where the subscripts on the MRS expressions indicate evaluation at different consumption bundles.

To proceed further, suppose that Figure 3a applies, so that the city has just a single generation of dwellings, with the age function exhibiting no jumps (this Figure is an enlarged version of 2a). Then, the location pattern of the two groups depends on the relative magnitudes of the slopes in (3) and (4), following well-known principles. If the rich slope is algebraically 
larger, then the rich outbid the poor for housing far from the CBD, with the poor outbidding the rich close to the CBD. When the bid-rent curves are upward sloping, as assumed, this slope relationship means that the rich curve is steeper than the poor curve. Examples of the resulting bid-rent curves are shown in Figure 3b, with the dotted curve belonging to the rich group. ${ }^{6}$

When Figure $3 \mathrm{~b}$ is relevant, the model generates a traditional US-style location pattern, with the rich living in the suburbs, occupying newer dwellings, and the poor living close to the CBD, occupying older dwellings. This pattern is shown in Figure 3c, which graphs an index identifying the group residing at each location, with the value 1 corresponding to the rich and the value -1 corresponding to the poor. For convenience, the pattern shown in Figures $3 b$ and $3 c$ is referred to subsequently as the "rich-decentralization" case.

To appreciate the underlying assumptions required to generate the rich-decentralization case, consider (3) and (4). On the one hand, the higher income of the rich means that the timecost term in (3) is more negative than the term in (4), which tends to make the rich bid-rent curve less steep than the poor curve, favoring a central location for the rich. On the other hand, normality of housing services means that the MRS term in the second part of the slope expressions is larger for the rich than for the poor. Since the MRS term multiplies a positive expression, this difference tends to make rich curve steeper than the poor curve, favoring a suburban location for the rich. As a result, the forces at work in the model are similar to those present in the standard static urban framework with endogenous housing consumption. In other words, the higher time costs of the rich pull them toward central locations, while more favorable housing opportunities (in this case, younger dwellings) pull them toward the suburbs.

\footnotetext{
${ }^{6}$ If the bid-rent curves were instead downward sloping, Figure 3 would show the rich curve as less steep. Again, the sign of the slopes is not crucial for the analysis.
} 


\subsection{Gentrification}

The key insight from the model comes from investigating how redevelopment of centrally-located dwellings, as captured in the transition from Figure $2 \mathrm{a}$ to $2 \mathrm{~b}$, affects the pattern of location by income. The analysis shows that, in the rich-decentralization case, central redevelopment leads to gentrification, with some rich consumers moving into the central city.

To establish this property of the model, focus on a time $\hat{t}$ that satisfies $L<\hat{t}<2 L$, so that the city has two generations of dwellings, as in Figure $2 \mathrm{~b}$. Let $\hat{b}=b(\hat{t})$ denote the edge of the city, let $\hat{y}_{r}=y_{r}(\hat{t})$ and $\hat{y}_{p}=y_{p}(\hat{t})$ denote incomes, and let $\hat{x}$ denote the location of the boundary between the second and first-generation dwellings. Furthermore, let $\hat{x}^{-}$and $\hat{x}^{+}$ denote locations just to the left and right of $\hat{x}$.

Consider first the behavior of bid-rents as they cross the $\hat{x}$ boundary, focusing on the rich curve. These bid-rents must adjust to equate rich utilities at locations $\hat{x}^{-}$and $\hat{x}^{+}$, responding to the jump in age (and hence the drop in housing services) across these two locations. Thus, the equality

$$
v\left[\hat{y}_{r}(1-\tau \hat{x})-R_{\tau}\left(\hat{x}^{-}\right), h(0)\right]=v\left[\hat{y}_{r}(1-\tau \hat{x})-R_{\tau}\left(\hat{x}^{+}\right), h(L)\right]
$$

must hold, where the $\hat{t}$ argument of $R_{r}$ is suppressed for notational simplicity. But since $h(0)$, housing services from a new dwelling, is much larger than $h(L)$, services from a dwelling that is about to be replaced, (5) implies that $R_{\tau}\left(\hat{x}^{-}\right)$must be much larger than $R_{\tau}\left(\hat{x}^{+}\right)$to equate utilities between $\hat{x}^{-}$and $\hat{x}^{+}$. Since the same conclusion holds for the poor bid-rent, it follows that both curves show downward discontinuities at $\hat{x}$, as seen in Figure $4 \mathrm{~b}$. 
The key second conclusion is that, if the rich outbid the poor for housing at $\hat{b}$, then they must also offer a higher bid for housing at $\hat{x}^{-}$. Thus, when the city has second generation dwellings, the rich must outbid the poor for the outermost of these dwellings, implying the existence of an area of gentrification in the central city. To establish this conclusion, note that since dwelling age equals zero at both $\hat{x}^{-}$and $\hat{b}$, consumption of $c$ must be the same at both locations in order to equate utilities, a condition that holds for both rich and poor. From the budget constraints, the bid-rents must satisfy the following equalities:

$$
\begin{aligned}
& \hat{y}_{r}(1-\hat{\imath})-R_{r}\left(\hat{x}^{-}\right)=\hat{y}_{r}(1-\hat{\imath})-R_{r}(\hat{b}) \\
& \hat{y}_{p}(1-\hat{\imath})-R_{p}\left(\hat{x}^{-}\right)=\hat{y}_{p}(1-\hat{\imath})-R_{p}(\hat{b})
\end{aligned}
$$

But subtracting (6) from (7) yields

$$
R_{r}\left(\hat{x}^{-}\right)-R_{p}\left(\hat{x}^{-}\right)=R_{r}(\hat{b})-R_{p}(\hat{b})+\left(\hat{y}_{r}-\hat{y}_{p}\right) \tau(\hat{b}-\hat{x})>R_{r}(\hat{b})-R_{p}(\hat{b}) .
$$

Eq. (8) says that the rich-poor bid-rent differential is larger at $\hat{x}^{-}$than at $\hat{b}$, which implies that if the rich outbid the poor at $\hat{b}$, as assumed, they also do so at $\hat{x}^{-}$. This conclusion follows because the willingness-to-pay for housing of a given age rises faster for the rich than for the poor as distance falls, a consequence of their higher time costs. Summarizing yields

Proposition 1. When a growing urban area characterized by the rich-decentralization case reaches the point where second-generation dwellings appear in the central city, gentrification occurs, with rich households occupying the outermost of these dwellings.

Proposition 1 is illustrated in Figure 4, which pertains to a slightly earlier time than Figure $2 \mathrm{~b}(t$ $=88.3)$. Note that, while the rich-poor bid-rent differential is larger at $\hat{x}$ than at $\hat{b}$ from (8), this difference is small enough to be indistinguishable in the Figure (recall that the dotted curve belongs to the rich). 
Figure 4 shows a gentrification pattern in which rich households occupy all of the city's second-generation dwellings, outbidding the poor over the entire distance range between the CBD and $\hat{x}$. This occupancy pattern is shown in Figure 4c. However, as the second-generation area expands outward, with its oldest dwellings approaching the end of their lifespans, poor households will reappear in the city center, being the highest bidders for dwellings in the innermost area. This outcome in shown in Figure 5, which pertains to $t=120.8$. Thus, moving away from the CBD, the location pattern is poor-rich-poor-rich, as seen in Figure 5c. ${ }^{7}$ This pattern easily generalizes to a city with an arbitrary number of dwelling generations. ${ }^{8}$

For a location pattern like that in Figure 5c, an additional result on occupancy patterns across dwelling generations can be established via the argument leading to Proposition 1:

Proposition 2. In the rich-decentralization case, the critical age beyond which occupancy switches from rich to poor is older in higher generation dwellings (those closer to the city center) at a given date in the city's evolution.

(see the appendix for a proof). Thus, the oldest dwelling containing a rich household will be older in the central area of a city, where higher-generation dwellings are located, than in the suburbs. The intuitive reason is that, because willingness-to-pay (holding age constant) rises relatively rapidly for the rich as distance falls, they are able to bid away housing farther up into the age distribution in later generation dwellings, which are located closer to the CBD.

As can be seen from the above analysis, all the qualitative properties of the model can be derived once a $T(x)$ function like that in Figure 1 is specified. This function is derived by considering the initial development decision of the property owner, which involves converting

\footnotetext{
${ }^{7}$ Cyclical location patterns like this one also emerge in the model of Bartolomé and Ross (2004), where the existence of separate political jurisdictions can disrupt an otherwise monotonic relation between income and distance.

${ }^{8}$ It should be noted that the model also admits an extreme version of gentrification, where the rich entirely disappear from the suburbs once the second-generation area in the central city becomes large enough. In this case, the initial location pattern by income is completely reversed, at least temporarily, as the city grows.
} 
land from agricultural to urban use. Assuming perfect foresight, this decision, in turn, requires computation of the present value of profit from an infinite sequence of dwellings, taking account of the transition from rich to poor occupancy over each dwelling's life cycle. To complete the analysis of the model, this calculation is presented in the appendix for a special case, and the $T(x)$ function is derived. Parameterization of this special case then yields the diagrams shown in the previous Figures.

\section{Econometric Model}

\subsection{Basics}

In contrast to the model, real cities have a distribution of incomes rather than just two income groups, and dwellings in any given neighborhood do not share a common age but instead exhibit a range of ages. Recognizing these facts, the dependent variable for the regression analysis is a census tract's "relative income" in 2000 , equal to average family income in the tract divided by the average family income for the MSA. Income values are taken from the Geolytics Inc. Neighborhood Change (NCBD) database. In addition, dwelling ages are captured by the age distribution of the housing stock, as measured by the shares of dwellings in a tract falling in different age ranges (see below). A tract's distance from the CBD is computed using geographic information software (MapInfo and MapBasic), and the CBD is identified using a populationdensity criterion. ${ }^{9}$

The model outlined above generates two empirical hypotheses that motivate the empirical work. These hypotheses are: (i) holding distance fixed, an increase in dwelling age tends to reduce neighborhood income, and (ii) holding age fixed, a decrease in distance tends to raise

\footnotetext{
${ }^{9}$ The CBD is defined as the centroid of the Census tract with the highest population density, and distance from the centroid of a given tract to this point is computed. Population densities are generated using GIS software.
} 
neighborhood income (Proposition 2). To test these hypotheses, we estimate regressions of the following form:

$$
\mathrm{y}_{2000, \mathrm{j}}=\mathrm{D}\left(x_{\mathrm{j}} ; \delta_{x}, \gamma_{\mathrm{MSA}}\right)+\omega_{2000, \mathrm{j}}
$$

and

$$
\mathrm{y}_{2000, \mathrm{j}}=\mathrm{D}\left(x_{\mathrm{j}} ; \delta_{x}, \gamma_{\mathrm{MSA}}\right)+\mathrm{A}\left(a_{2000, \mathrm{j}} ; \theta\right)+\omega_{2000, \mathrm{j}}
$$

In these regressions, $y_{2000, \mathrm{j}}$ is the relative income of neighborhood $j$ (census tract $j$ ) in $2000, x_{\mathrm{j}}$ is the tract's distance from the CBD, $a_{2000, j}$ represents the age distribution of the housing stock in 2000, and $\omega_{2000, j}$ is an error term. D is a function that describes the relationship between neighborhood economic status and distance, with $\delta_{x}$ representing the distance coefficient(s) and $\gamma_{\mathrm{MSA}}$ representing an MSA fixed effect. Similarly, $\mathrm{A}$ is a function describing the relationship between economic status and age, with $\theta$ being a coefficient vector.

Our strategy is to estimate both (9) and (10) and then to compare the effects of distance on neighborhood economic status. If the dwelling age distribution has no effect on the pattern of location by income, then the estimated influence of distance should be alike in the two regressions. Otherwise, (9) is misspecified and yields a biased estimate of the distance effect, with a consistent estimate instead given by (10). The coefficients from (10) reveal how neighborhood economic status would vary with distance if the effect of dwelling age were eliminated. Concretely, the resulting distance effect is the one that would emerge if all of the city's dwellings were of the same age.

\subsection{Endogenous dwelling ages}

While the model above treats the timing of housing redevelopment and thus dwelling ages as exogenous, redevelopment would occur endogenously in a more general model. In such a 
model, the housing developer would compare the gain in profit from continuing to operate an aging dwelling to the lost profit (in present value terms) from a slight delay in redevelopment. The dwelling is replaced when these two quantities are equal. ${ }^{10}$

Although endogenous redevelopment by itself would not materially change the spatial implications of the analysis, adding a stochastic element to such a model is a potential source of econometric trouble. For example, suppose unobservable neighborhood amenities exist and that they are valued more highly by the rich than by the poor. Then, since the bid-rent offer of the rich will be relatively high in a high-amenity neighborhood, developers will be eager to redevelop its aging dwellings, switching occupancy from the poor to the high-paying rich. Under this scenario, the error term $\omega_{\mathrm{j}, 2000}$ will tend to be large in high-amenity neighborhoods, indicating higher than average incomes. But since quick redevelopment means that dwelling ages will also tend to be low, the result is negative correlation between age and the error term, leading to inconsistent parameter estimates in (10).

Our solution to this problem is to instrument for the potentially endogenous age distribution of the housing stock. This approach is implemented in the simplest possible fashion by replacing the age variables $a_{\mathrm{j}, 2000}$ in (10) by the neighborhood age distribution measures from a previous decade. In other words, the new variable $a_{\mathrm{j}, 2000-\mathrm{k}}$ is substituted in $(10)$, where $k$ indicates a decadal lag, with $k=1$ corresponding to 1990 and $k=2$ corresponding to 1980 . We focus primarily on results using the 1980 age measures. Results based on specifications that use 1990 and 2000 values for $a_{\mathrm{j}}$ are similar, as will be discussed below.

The lagged age distribution measures are good instruments because, for dwellings not redeveloped, the year-2000 age is simply the year-1980 age plus 20. This link ensures

\footnotetext{
${ }^{10}$ Brueckner (1981) models this behavior in a steady-state environment without urban growth, while Braid (2001)
} 
correlation between the 1980 and year-2000 dwelling age distributions. In addition, the 1980 dwelling age distribution will be exogenous to unanticipated amenity shocks in the subsequent twenty years, reducing any possible correlation between the 1980 age measures (which depend on 1980 amenities by the above argument) and $\omega_{\mathrm{j}, 2000}$ in (10).

Note that employing the lagged age measures is possible because our data have all been uniformly coded to year-2000 census tract boundaries, circumventing intercensus boundary changes. ${ }^{11}$ An added bonus to using lagged age measures is that it enables us to forecast change in neighborhood economic status between 2000 and 2020, as will be clarified below.

\section{Estimation Results}

\subsection{The linear specification}

Because of its familiarity from a host of past studies, we first present results based on a linear specification of the D function in (9) and (10), which is written

$$
\mathrm{D}\left(x_{\mathrm{j}} ; \delta_{x}, \gamma_{\mathrm{MSA}}\right)=\gamma_{\mathrm{MSA}}+\delta_{x} x_{\mathrm{j}}
$$

In this expression, economic status in the center of the city, where $x_{\mathrm{j}}$ is zero, is given by an MSA-specific constant, $\gamma_{\mathrm{MSA}}$. While this specification reveals average patterns in the data, it is restrictive in imposing a monotonic relationship between distance and economic status. In contrast, the theory from Section 2 suggests that economic status may vary irregularly with distance in response to the cyclical pattern of redevelopment. This deficiency is remedied in a more flexible specification used below.

Table 1 presents results from several versions of the linear distance regression. Column 1 presents the most restrictive version and includes distance from the CBD (Distance) as the

treats the more-difficult non-steady-state case. While both models assume a single income group, their approach could be adapted to the present two-group case, with some additional complications. 
only regressor apart from the MSA fixed effects. Consistent with conventional wisdom, the coefficient on distance is positive and highly significant. The point estimate implies that a onemile increase in distance from the CBD increases the relative income of a neighborhood by 0.0018, indicating that income rises relative to the MSA mean by about 0.2 percent, a small magnitude.

Column 2 extends the model by adding a variable that interacts distance from the CBD with the number of census tracts in the MSA, where tract counts are measured in 1,000 units. This variable, whose coefficient is positive and significant, allows the relationship between distance from the $\mathrm{CBD}$ and neighborhood economic status to differ with the size of the metropolitan area. The point estimates in column 2 imply that, with each extra mile of distance from the $\mathrm{CBD}$, neighborhood economic status remains essentially unchanged in a city with 100 tracts (and a population near 500,000) once the direct effect of Distance is taken into account, while increasing by 0.3 percent in the city with 1000 tracts (and a population near 5 million). Although these effects still are modest in size, they suggest that larger, older cities are more likely to experience spatial disparities in economic status.

Column 3 begins to address our theory in earnest by including controls for the tract-level age distribution of the housing stock. We start by presenting results using year-2000 age measures, and then shift to 1980 age variables to address the concern about endogeneity of year2000 dwelling ages. For 2000, controls are provided for the percentage of tract dwellings that were 0 to 4 years, 5 to 9,10 to 19,20 to 29,30 to 39,40 to 49,50 to 59 , and 60 or more years in age in 2000 . The age 50 to 59 category is omitted to avoid perfect collinearity.

\footnotetext{
${ }^{11}$ See the website for Geolytics Inc. for detail: www.geolytics.com.
} 
Relative to dwellings 50 to 59 years old, column 3 shows that newer dwellings typically have a positive and significant effect on the economic status of the neighborhood, with the effect mostly declining as the age category rises. Consistent with that pattern, the coefficient on dwellings aged 60 and over is negative and significant, implying this category of dwellings has the most negative association with neighborhood economic status.

Turning to the Distance and interactive variables, results are striking. Having controlled for the age distribution of the housing stock, the direct effect of Distance is now a highly significant -0.0037 , an effect ten times as large as in column 2 . The interactive term, by contrast, is positive and equals 0.0016 , a smaller value than in column 2 . These estimates imply that, if all housing were of the same age, neighborhood economic status would fall with distance from the city center in all but the largest MSAs (where the tract variable is somewhat larger than 2).

Column 4 of Table 1 shows the effect of using 1980 age measures. For 1980, the oldest age class is 40 -and-older, and the omitted category is $30-39$ years. With all the age coefficients positive, dwellings in the second oldest category (the omitted group) exert the most depressing effect on neighborhood economic status. ${ }^{12}$ Turning to the distance effects, the two coefficients decline in absolute value relative to column 3, but the point estimates still imply that neighborhood economic status falls with distance from the city center in all but the largest MSAs. While this conclusion is thus qualitatively the same as in column 3, the more modest negative effect of distance suggests that age endogeneity may slightly bias the estimates based on year-2000 age measures.

\footnotetext{
${ }^{12}$ Note that dwellings aged 40 and over in 1980 are 60 and over in 2000. Many of these dwellings may have been redeveloped subsequent to 1980 , contributing to an in-migration of higher-income families. This possibility could account for why the second oldest category in 1980 has the most negative impact on year-2000 neighborhood economic status.
} 
To explore these patterns further, Table 2 presents separate regressions for four different size categories of MSAs: those with fewer than 100 census tracts, with 100 to 500 census tracts, 500 to 1,000 census tracts, and more than 1,000 census tracts (this change allows deletion of the interaction variable). Consistent with the previous results, when the age distribution of the housing stock is omitted, neighborhood economic status rises with distance from the CBD at a modest but statistically significant rate in all but the third size category. When the year-2000 age measures are added to the regressions, the coefficient on Distance becomes significantly negative in all but largest size category. If 1980 age measures are used instead, the distance coefficient falls in absolute value in each size category, but becomes significantly negative only in the third category.

These patterns, which recapitulate the results from Table 1, yield a clear message. After controlling for the age distribution of the housing stock, the tendency of neighborhood economic status to rise with distance from the $\mathrm{CBD}$ is reduced and sometimes completely reversed, with a negative distance effect emerging instead. However, the magnitude of these distance effects, be they positive or negative, is modest.

As a final point, it should be noted that the change in the distance coefficients in Tables 1 and 2 after controlling for the dwelling age distribution implies that dwelling age is negatively correlated with distance from the city center. Given this correlation, which is confirmed by results presented below, failing to control for dwelling ages leads to an upward bias in the estimated effect of distance on neighborhood economic status. 


\subsection{The distance-dummy specification}

In this section, we adopt a more flexible specification of the $\mathrm{D}$ function by breaking distance into discrete bands, each represented by a dummy variable. The $\mathrm{D}$ function is now given by

$$
\begin{aligned}
\mathrm{D}\left(x_{\mathrm{j}} ; \delta_{x}, \gamma_{\mathrm{MSA}}\right)=\gamma_{\mathrm{MSA}} & +\delta_{0 t 01} x_{0 \mathrm{tol} 1}+\ldots+\delta_{9 t 010} x_{9 t 010} \\
& +\delta_{10 t 012} x_{10 \mathrm{to} 12}+\ldots+\delta_{38 t o 40} x_{38 \mathrm{to} 40}+\delta_{40 \mathrm{orMore}} x_{40 \mathrm{orMore}}
\end{aligned}
$$

where the bands are one mile in width up to 10 miles and two miles in width from 10 to 40 miles, with 40-miles-or-more as the final category (the $x$ 's denote the dummy variables). This specification allows for a very general relationship between distance and neighborhood economic status and accommodates the theory from section 2 quite well. Note that when the age distribution of the housing stock is omitted, as in (9), there is no role for the MSA fixed effect, which drops out of the model. However, when age measures are included, as in (10), then the fixed effect captures the influence of the omitted age category for the MSA.

To begin exploring the results under this new specification, consider Figure 6, which plots average dwelling age within each distance band for the four city-size categories. Figure 6 shows that average dwelling age generally declines with distance from the CBD for each size category, with some notable variation across categories. The interval of lower ages near the CBDs of the largest cities testifies to the kind of central redevelopment envisioned in the model of section 2. The long flat range of average age in the largest cities is also noteworthy, as is the rapid age decline with distance in the smallest category.

Figure 7 shows the spatial pattern of relative incomes in the four size categories, providing the analog to the basic regressions in Table 2 for the distance-dummy specification. Specifically, the graph shows the pattern of distance-dummy coefficients from a regression using 
the $\mathrm{D}$ specification in (11). Figure 7 shows that neighborhood economic status tends to be relatively low close to the $\mathrm{CBD}$, achieves a global peak at some intermediate distance, and then declines in outlying portions of the MSAs that are likely rural in nature. The difference in economic status between central cities and suburbs is large. Among the largest cities, for example, from trough to peak, the central-city/suburban difference in economic status is roughly 50 percent of MSA mean income (1.3 versus 0.8 in the figure).

The patterns in Figure 7 are consistent with the mostly positive distance coefficients in the basic regressions of Table 2. Note also that the peak in neighborhood economic status tends to lie farther away from the CBD in the largest cities, matching the relatively distant locations of neighborhoods with the youngest dwellings in these cities. ${ }^{13}$ Overall, these plots confirm that U.S. central cities tend to be poor relative to the suburbs, and that it is important to allow for a nonlinear and non-monotonic influence of distance on neighborhood economic status.

Figure 8 plots distance-dummy coefficients for each of the city-size categories when controls are added for the age distribution of the housing stock. ${ }^{14}$ Because of the potential

\footnotetext{
${ }^{13}$ For example, among cities with fewer than 100 tracts, neighborhood economic status peaks at roughly 6 miles from the city center. But among cities with more than 1,000 census tracts, neighborhood economic status peaks at roughly 26 miles from the city center.

${ }^{14}$ Recall that the relative income in a given tract is calculated by dividing average tract income by the MSA mean. Relative income therefore averages to 1 across tracts within each MSA, by construction. Similarly, for a given MSA, when dwelling ages are omitted from the regression model as in Figure 7, the distance dummy coefficients average to 1 upon weighting each coefficient by the sample share of tracts in its corresponding distance band. To be precise,

$$
1=\hat{\delta}_{0 t o 1} \bar{s}_{0 \mathrm{tol} 1}+\ldots+\hat{\delta}_{9 t 010} \bar{S}_{9 \mathrm{to} 10}+\hat{\delta}_{10 t 012} \bar{s}_{10 \mathrm{to} 12}+\ldots+\hat{\delta}_{38 t 040} \bar{s}_{38 \mathrm{to} 40}+\hat{\delta}_{40 \mathrm{orMore}} \bar{S}_{40 \mathrm{orMore}}
$$

where $\bar{S}_{\mathrm{j}}$ is the sample share of tracts in distance band $\mathrm{j}$ and $\hat{\delta}_{\mathrm{j}}$ is the corresponding estimate of relative income for that location. It is worth emphasizing that the estimated values for $\hat{\delta}_{\mathrm{j}}$ from this model reflect the influence of the entire dwelling age distribution within a given MSA. But, upon adding controls to the model for the dwelling age distribution, the distance dummy coefficients measure neighborhood economic status associated with the omitted dwelling age category, in this case, 30 to 39 years. Holding distance constant, economic status associated with age 30 to 39 year old dwellings differs from that associated with the average dwelling age distribution. For that reason, upon controlling for the dwelling age distribution, a weighted average of the estimated distance dummy coefficients (using $\bar{S}_{\mathrm{j}}$ as the weights as above) will equal $k$, where $k$ typically differs from 1 . To ensure comparability between the underlying "standard" aged dwelling in Figures 7 and 8, the estimated distance coefficients obtained upon
} 
endogeneity of dwelling ages, 1980 age measures are used. Results based on the 1990 and year2000 dwelling age distributions are similar and are presented in Appendix B for comparison. ${ }^{15}$ Note also that the vertical scales in Figures 7 and 8 are the same in order to facilitate comparison.

Several striking patterns are apparent in Figure 8. First, controlling for the age distribution of the housing stock, spatial variation in neighborhood economic status is substantially reduced for each city-size category. Second, for each size category, economic status is roughly constant over an extended area, which stretches from roughly 3 to 20 miles for the three smaller size categories and from roughly 8 to 30 miles for the largest category. Third, for cities of all sizes, even after controlling for the age distribution of the housing stock, neighborhood economic status rises with distance from the CBD until flattening out.

A fourth key implication of these figures can be seen by subtracting the relative income values in Figure 7 from the values in Figure 8. This difference, which is plotted in Figure 9, shows how relative income would change in each distance band if the dwelling age distribution were the same in each neighborhood, matching the average distribution in the city. For example, referring to the curve for the largest city size category, relative income in the band at 3 miles would be 0.1 , or 10 percent, higher if that distance band had an average dwelling age distribution instead of the old dwellings that were actually present in 1980 (see Figure 6). Conversely, relative income in the distance band at 26 miles would have been more than 15 percent lower had the young dwellings in that distance band (see Figure 6) been replaced by average dwellings.

controlling for dwelling age were adjusted by adding $1-k$ to each estimate. It is those estimates that are plotted in Figure 8. This procedure generalizes to the presence of multiple MSAs in the sample given the linearity of the problem.

${ }^{15}$ The plots in Appendix B mirror those in Figure 9, which is discussed below. 
For the largest cities, this comparison of two distance bands reflects a general property made clear by Figure 9: if the spatial variation in dwelling ages were eliminated, economic status would generally rise near the $\mathrm{CBD}$ and fall in the suburbs. This conclusion follows because the largest-city curve starts out in the positive range near the CBD and crosses forever into negative territory at an intermediate point. As can be seen from Figure 9, this same pattern, where economic status rises in the center and falls in the suburbs, approximately characterizes the remaining size categories. ${ }^{16}$ The magnitudes of these effects are also important, especially for the largest cities. Among those MSAs, eliminating spatial variation in dwelling ages would reduce central city/suburban differences in economic status by 25 percent of MSA mean income, roughly half of the actual disparity.

These conclusions mirror the findings of the linear distance specification, which showed that the rise in economic status over distance was attenuated after controlling for age affects. Thus, the empirical results substantiate the key claim made above in the introduction: if the influence of dwelling age were eliminated, the disparities in income between central city and suburban neighborhoods would be substantially reduced.

\subsection{Other factors that affect location by income}

The discussion thus far makes clear that the tendency of cities to develop and redevelop from the center outward over time has an important effect on the location of low- and highincome households. This effect arises because older housing typically provides lower housing services, causing higher-income households to seek out newer dwellings. If the dwelling age distribution were the only determinant of where low- and high-income neighborhoods are found,

\footnotetext{
${ }^{16}$ Note that the curves for the two smallest size categories eventually pass back into positive territory far from the $\mathrm{CBD}$, in regions that are likely predominantly rural.
} 
then removing the influence of dwelling ages should result in similar levels of economic status across neighborhoods regardless of distance. If, however, all employment is concentrated in the $\mathrm{CBD}$ and the time cost of commuting matters, then upon removing the influence of dwelling ages, higher-income households would outbid low-income households for central locations, as discussed in Section 2. In that case, neighborhood economic status should fall with distance from the city center. In reviewing Figure 8, it is evident that neither of these patterns prevails. This outcome suggests that additional factors outside of our model contribute to the pattern of location by income. Two sets of such factors are now considered.

Notice once more that in Figure 8, neighborhood economic status is low near the CBD even after controlling for the dwelling age distribution. This pattern could be consistent with the dominance of the "standard" housing-based force discussed in the introduction, where cheap housing (on a per-square-foot basis) pulls the rich toward the suburbs. However, as noted earlier, the results of Wheaton (1977) and Glaeser, Kahn, and Rappaport (2001) undermine this argument. As a result, the lure of central-city public transit, as emphasized by Glaeser, Kahn and Rappaport (2001), or the absence of central amenities, as emphasized by Brueckner, Thisse and Zenou (1999), likely account for the continued low economic status of the central city even upon controlling for the age distribution of the housing stock.

But what might account for the extended relatively flat sections in Figure 8 over which economic status changes little with distance? One likely explanation is that most U.S. cities in 2000, and especially the larger ones, are not monocentric. Instead, a common phenomenon has been the emergence of important suburban employment subcenters, or so-called "edge cities" (Garreau (1991)). With the creation of these suburban centers, workers often can then choose whether to commute to the downtown core or to more outlying areas, weakening the 
$\mathrm{CBD} /$ suburban distinction in the household's location problem. That effect, in turn, leads to a flattening of the underlying bid-rent functions and a corresponding flattening of the spatial variation in neighborhood economic status. ${ }^{17}$

\subsection{Will future downtowns be rich?}

We return now to the question posed in the title of this paper: will the downtowns of U.S. cities achieve higher economic status in the future? This question is addressed by forecasting the spatial pattern of neighborhood economic status in 2020 for the four different size categories of cities. To see how this exercise is carried out, let

$$
\mathrm{y}_{2000 \mathrm{j}}=\gamma_{\mathrm{MSA}}+\delta \mathrm{D}_{\mathrm{j}}+\theta a_{\mathrm{j}, 1980}+\omega_{\mathrm{j}, 2000}
$$

represent the equation estimated under the distance dummy approach, where $\delta \mathrm{D}_{\mathrm{j}}$ is a shorthand for (11). Recognizing that (12) relates neighborhood economic status in 2000 to the housing age distribution twenty years earlier, economic status in 2020 can be predicted by simply updating the equation. Assuming time invariance of the coefficients in (12), and substituting year-2000 age measures in place of $a_{\mathrm{j}, 1980}$, the equation then reads

$$
\mathrm{y}_{2020, \mathrm{j}}=\gamma_{\mathrm{MSA}}+\delta \mathrm{D}_{\mathrm{j}}+\theta a_{\mathrm{j}, 2000}+\omega_{\mathrm{j}, 2020}
$$

To illustrate the predicted change in neighborhood economic status, we compute the difference between the predicted 2020 relative incomes from (13) and the fitted 2000 incomes from (12), with the results plotted in Figure 10 for each distance band in four city-size categories. ${ }^{18}$

\footnotetext{
${ }^{17}$ Because the linear distance model forces the $\mathrm{CBD}$ to be the sole spatial reference point, the presence of employment subcenters further biases results from that model. Note, however, that results from the distancedummy model are largely free of such concerns. The reason is that each distance dummy coefficient reflects the influence of the complete vector of commute opportunities (and other distance-specific amenities) associated with that distance band. This tendency is especially clear when cities are radially symmetric, with a ring of subcenters at a given distance from the CBD. But even in a fully general case where cities are not radially symmetric, it is important to recognize that the key features of the estimates above are robust. In particular, note that the plots in Figure 9 are based on differences between estimates from Figures 8 and 7. The differencing procedure eliminates
} 
Will the future downtowns of American cities be richer than today? Figure 10 makes clear that the answer to this question depends on the size category to which a city belongs. Among the smallest MSAs, the passage of time is not expected to elevate the future economic status of the downtowns. If anything, the opposite is true, as the plots in Figure 10 suggest that economic status will fall by up to 4 percent in the 2 to 6 mile range.

At the opposite extreme are the largest MSAs, where several patterns are worth noting. First, over the 2000 to 2020 period, central-city economic status is expected to rise in these MSAs, with the gain ranging from 4 percent at the CBD to about 8 percent at a distance of roughly 6 miles. This pattern presumably reflects the combined effects of previous progress toward gentrification close to the center, which limits future income gains in these neighborhoods, as well as the likelihood that dwellings a bit farther out will be ripe for redevelopment by 2020 .

Beyond a distance of eight miles, the predicted change in economic status in the largest cities is negative, bottoming out at -10 percent at 26 miles. On net, therefore, the difference in economic status between central and suburban neighborhoods is expected to narrow by up to 18

(approximately) the influence of unobserved factors associated with a given distance band, yielding consistent estimates of the independent effect of dwelling age on neighborhood economic status.

${ }^{18}$ To implement this procedure a technical point must also be addressed. Because the dwelling age distribution in 2000 differs from that of 1980, differencing (13) and (12) and averaging over tracts within each MSA, yields,

$$
\overline{\mathrm{y}}_{\mathrm{MSA}, 2020}=\overline{\mathrm{y}}_{\mathrm{MSA}, 2000}-\theta\left(a_{\mathrm{MSA}, 1980}-a_{\mathrm{MSA}, 2000}\right)
$$

where the term in parentheses will typically differ from zero. In (N1), $\overline{\mathrm{y}}_{\mathrm{MSA}, 2000}$ is the MSA mean relative income as obtained from (12), while $\overline{\mathrm{y}}_{\mathrm{MSA}, 2020}$ is the MSA mean relative income as obtained from (13). Because $\overline{\mathrm{y}}_{\mathrm{MSA}, 2000}$ equals 1 by construction, $\overline{\mathrm{y}}_{\mathrm{MSA}, 2020}$ must differ from 1, which is equivalent to having changed the underlying MSAwide level of income. Our goal, however, is to simulate the location patterns of the year 2000 population having updated the stock of dwellings twenty years, ceteris paribus. Accordingly, to ensure that the implied underlying population characteristics remain unchanged, the individual tract relative income values as obtained from (13), denoted $\hat{\mathrm{y}}_{\mathrm{j}, 2020}$ below, are adjusted so that they average to 1 for each MSA:

$$
\tilde{\mathrm{y}}_{\mathrm{j}, 2020}=\hat{\mathrm{y}}_{\mathrm{j}, 2020}-\left[\overline{\mathrm{y}}_{\mathrm{MSA}, 2020}-1\right] \text {. }
$$


percent of MSA mean income, a large effect. Similar, but less dramatic, patterns are evident in the second and third size categories.

These patterns reflect the presence of predominantly older housing stocks in the central city and younger dwellings in the suburbs, patterns that were made clear in Figure 6. After twenty years of additional aging, some central-city housing will be redeveloped while the deteriorating condition of many suburban dwellings will reduce their appeal to higher income households. While these forces will reduce the spatial disparities in economic status, central cities will nevertheless continue to be poorer than suburban communities.

\section{Conclusion}

This paper has provided new insights into the process of gentrification by identifying a new factor, the age of the housing stock, that affects patterns of location by income. Since their high demand for housing services draws high-income households toward newer dwellings, such households will tend to be found in areas of the city where the housing stock is relatively young. While these areas will lie in the suburbs over much of a city's history, helping to explain the traditional suburban location of the rich, eventual redevelopment of aging dwellings in the center creates a young downtown housing stock that attracts high-income households, leading to gentrification. Note that, even though the precise timing of redevelopment may be partly endogenous, being dependent on other forces that draw high-income households to a neighborhood, renewal of the housing stock, and thus gentrification, is ultimately driven by the passage of time and the associated aging and obsolescence of the housing stock.

Having formed $\tilde{y}_{\mathrm{j}, 2020}$ for each individual census tract, we subtract off $\hat{\mathrm{y}}_{\mathrm{j}, 2000}$ (the individual tract relative income from (12)) and regress the difference on the distance dummy variables as before. Results are plotted in Figure 10. 
The empirical work in the paper provides substantial support for this new perspective. Our results show that, if the influence of spatial variation in dwelling ages were eliminated, central city/suburban disparities in neighborhood economic status would be reduced by up to 50 percent within American cities. In other words, if the housing age distribution were made uniform across space, reducing average dwelling ages in the central city and raising them in the suburbs, then neighborhood economic status would shift in response, rising in the center and falling in the suburbs. It should be emphasized that these findings are robust to whether we control for contemporaneous, one-, or two-decade lagged measures of the age distribution of the housing stock. This outcome suggests that our results are largely free of biases that might result from the possibly endogenous character of dwelling ages.

Drawing on two-decade lagged measures of dwelling ages further allows us to forecast future changes in economic status in response to evolution of the housing stock through 2020. For small MSAs, the findings indicate that their central cities will likely decline relative to their suburbs, although the anticipated shift is relatively modest. In sharp contrast, for the larger MSAs, central-city economic status is expected to rise relative to that of the suburbs by up to 20 percent of MSA mean income, a large effect. Nevertheless, while this shift implies ongoing gentrification in the central cities of larger metropolitan areas, these neighborhoods are expected to remain poor, on average, relative to the suburbs.

Explaining patterns of location by income is a task that has absorbed substantial research effort by urban economists over the years. Despite this effort, consensus on a robust explanation for observed location patterns has been elusive. We hope that the perspective offered in this paper advances the state of this inquiry while providing a glimpse into the future of American cities. 


\section{References}

Aaronson, Daniel, "Neighborhood Dynamics," Journal of Urban Economics, 49, 1-32 (2001).

Alonso, William, Location and Land Use, Cambridge: Harvard University Press (1964).

de Bartolomé, Charles A.M., and Stephen L. Ross, "Equilibria with Local Governments and Commuting: Income Sorting vs Income Mixing," Journal of Urban Economics 54, 1-20 (2003).

Braid, Ralph M., "The Comparative Statics of a Filtering Model of Housing with Two Income Groups," Regional Science and Urban Economics 16, 437-448 (1986).

Braid, Ralph M., "Spatial Growth and Redevelopment with Perfect Foresight and Durable Housing," Journal of Urban Economics 49, 425-452 (2001).

Brueckner, Jan K., "Residential succession and Land-Use Dynamics in a Vintage Model of Urban Housing," Regional Science and Urban Economics, 10, 225-240 (1980).

Brueckner, Jan K., “A Dynamic Model of Housing Production," Journal of Urban Economics 10, 1-14 (1981).

Brueckner, Jan K., Jacques-François Thisse, and Yves Zenou, "Why is Central Paris Rich and Downtown Detroit Poor? An Amenity-Based Theory," European Economic Review 43, 91-107 (1999).

Coulson, Edward and Eric Bond, "A Hedonic Approach to Residential Succession," Review of Economics and Statistics, 433-443, (1990).

Galster, George, "William Grigsby and the Analysis of Housing Sub-markets and Filtering," Urban Studies, 33, 1979-1805 (1996).

Garreau, Joel, Edge City: Life on the New Frontier, New York: Doubleday (1991).

Glaeser, Edward L. and Joseph Gyourko, “Urban Decline and Durable Housing,” Journal of Political Economy 113, 345-375 (2005).

Glaeser, Edward L., Matthew E. Kahn, and Jordan Rappaport, "Why Do the Poor Live in Cities?," National Bureau of Economic Research working paper 7636, April 2000.

Kern, Clifford R., 1981, "Upper-Income Renaissance in the City: Its Sources and Implications for the City's Future," Journal of Urban Economics 9, 106-124 (1981).

Leroy, Stephen F. and Jon Sonstelie, "Paradise Lost and Regained: Transportation Innovation, Income, and Residential Location, Journal of Urban Economics 13, 67-89 (1983). 
Mills, Edwin S., “An Aggregative Model of Resource Allocation in a Metropolitan Area, American Economic Review 57, 197-210 (1967).

Muth, Richard F., Cities and Housing, Chicago: University of Chicago Press (1969).

Rosenthal, Stuart and Robert Helsley. "Redevelopment and the Urban Land Price Gradient," Journal of Urban Economics 35, 182-200 (1994).

Rosenthal, Stuart, “Old Homes, Externalities, and Poor Neighborhoods: A Model of Urban Decline and Renewal," unpublished paper, Syracuse University (2005).

Sweeney, James L., “A Commodity Hierarchy Model of the Rental Housing Market,” Journal of Urban Economics 1, 288-323, (1974)

Weicher, John, and Thomas Thibodeau, "Filtering and Housing Markets: An Empirical Analysis,” Journal of Urban Economics, 23, 21-40 (1988).

Wheaton, William C., "Income and Urban Residence: An Analysis of Consumer Demand for Location," American Economic Review 67, 620-631 (1977). 


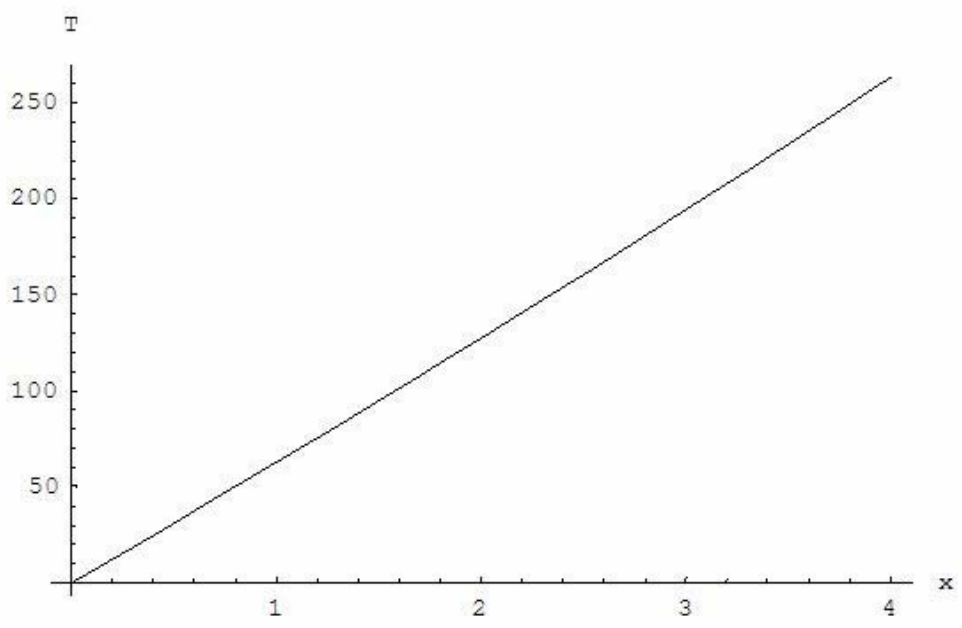

Figure 1: The T function 

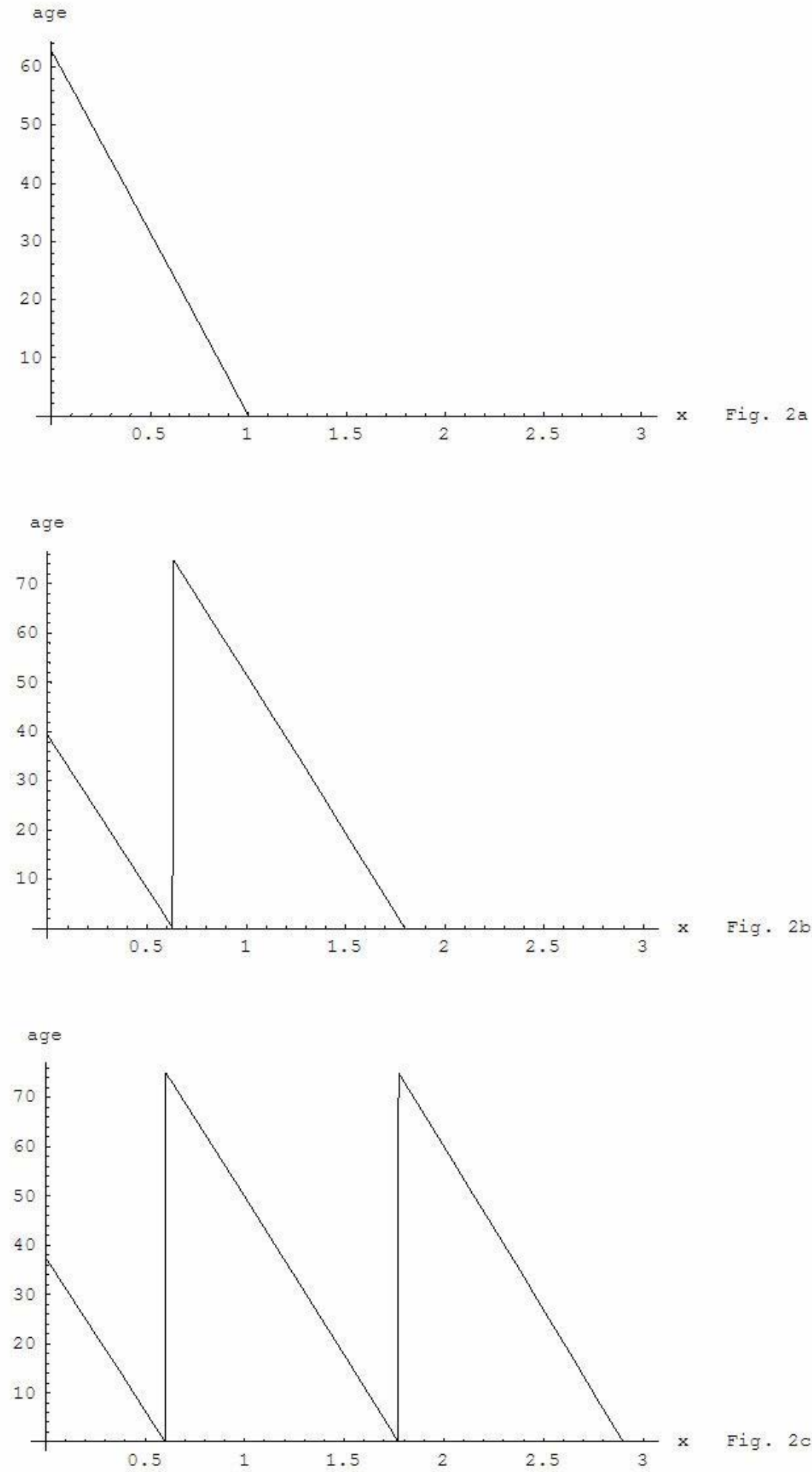

Figure 2 : Dwelling age patterns 

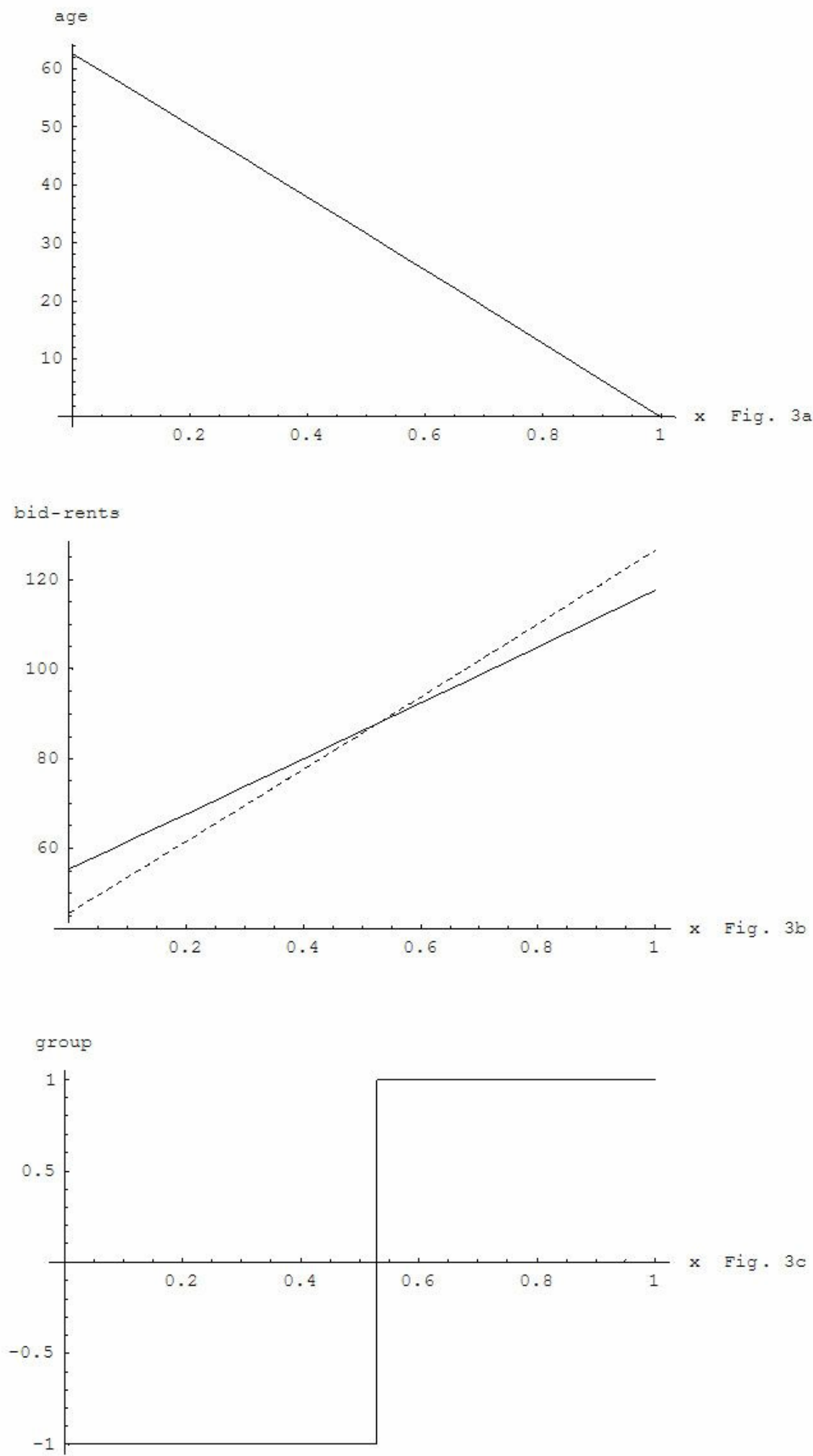

Figure 3 : Rich in suburbs 

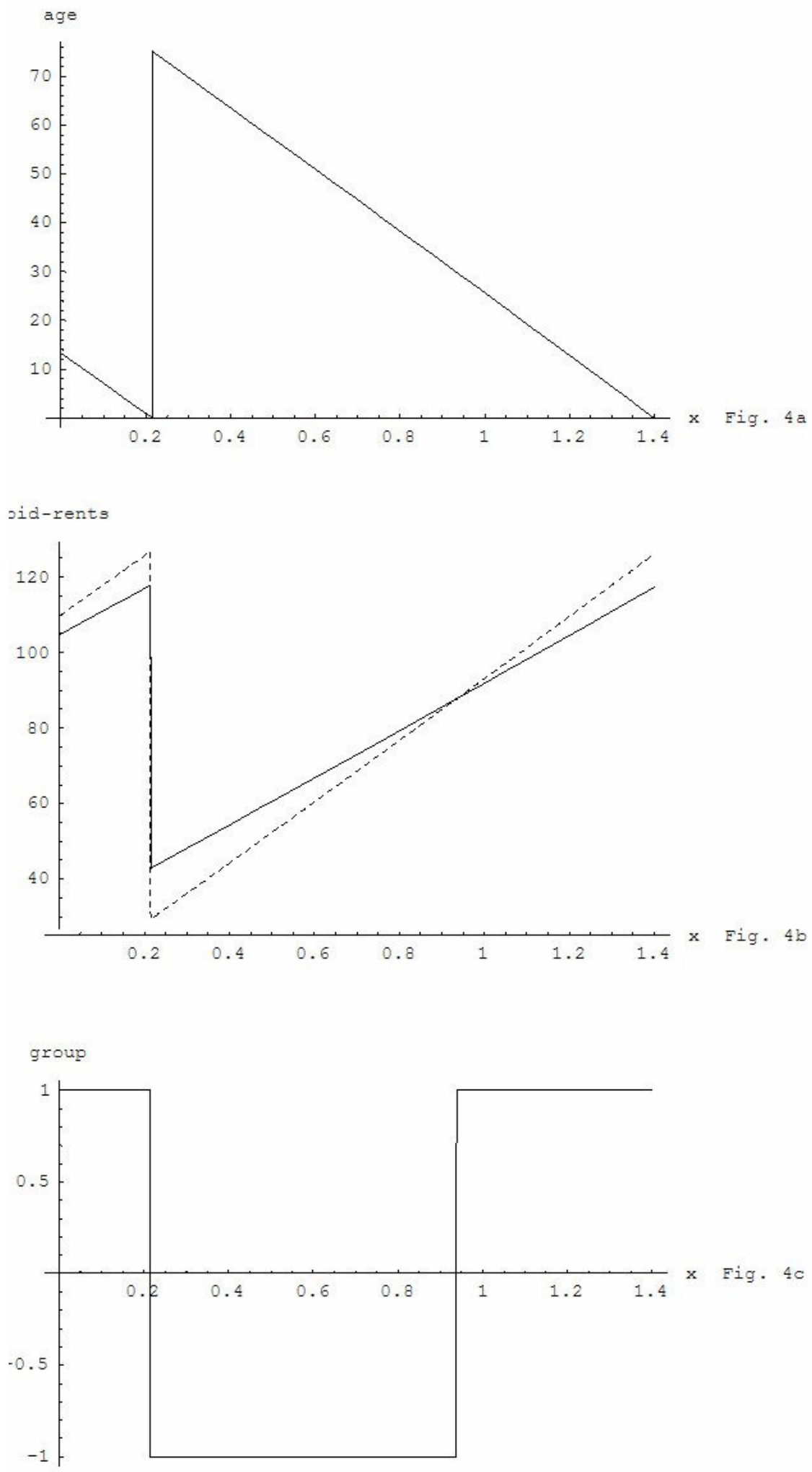

Figure 4 : Gentrification 

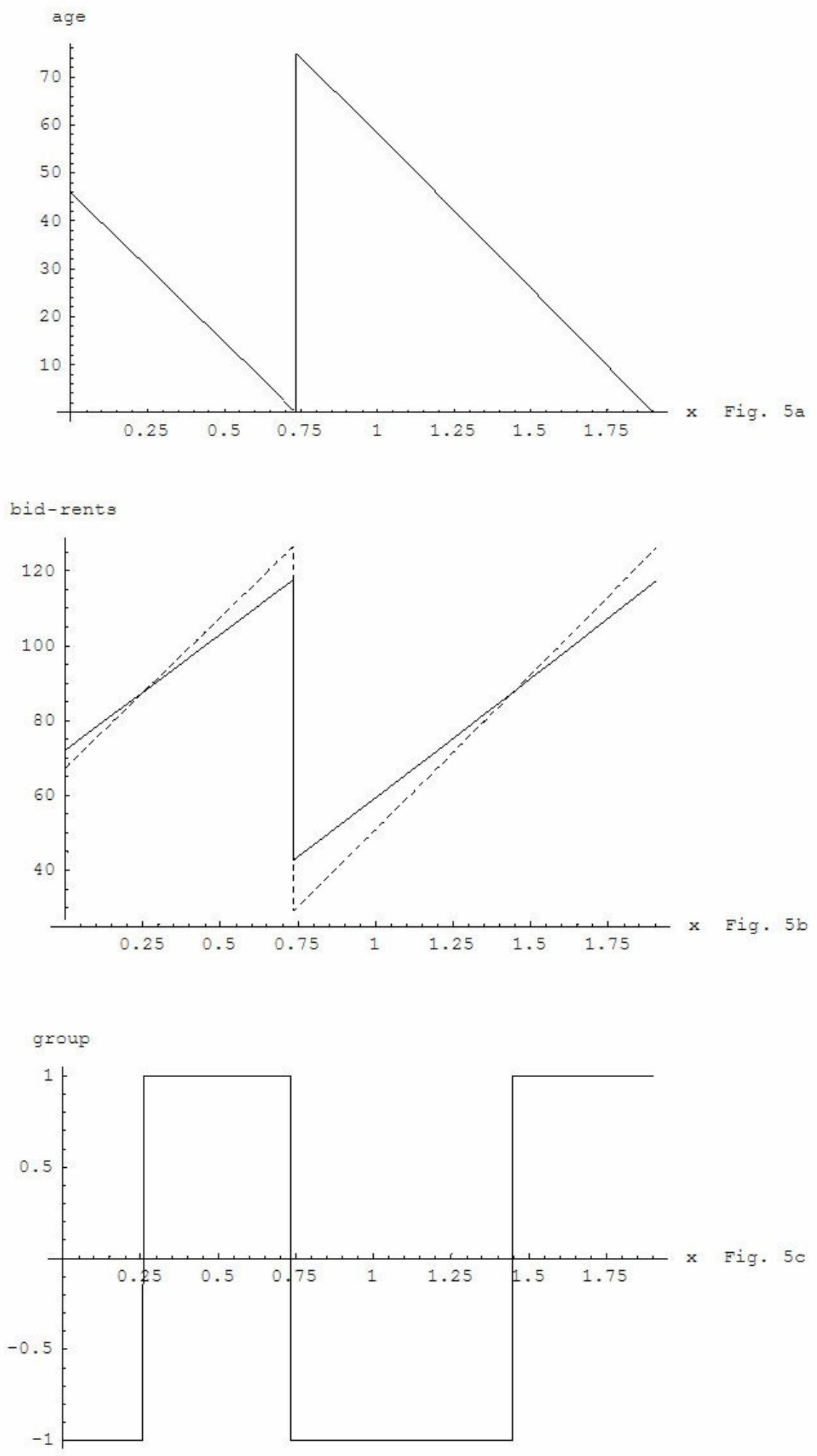

Figure 5 : Poor Regain Center 
Table 1: Neighborhood Economic Status For All MSAs

(Dependent variable is Year 2000 census tract average income relative to MSA average income; t-ratios in parentheses)

\begin{tabular}{|c|c|c|c|c|}
\hline & $\begin{array}{l}\text { Omit Age } \\
\text { Controls }\end{array}$ & $\begin{array}{l}\text { Omit Age } \\
\text { Controls }\end{array}$ & $\begin{array}{c}\text { Year } 2000 \text { Age } \\
\text { Controls }\end{array}$ & $\begin{array}{c}\text { Year } 1980 \text { Age } \\
\text { Controls }\end{array}$ \\
\hline \multirow[t]{2}{*}{ Distance (Miles from city center) } & 0.0018 & -0.0004 & -0.0037 & -0.0008 \\
\hline & $(9.08)$ & $(-1.22)$ & $(-12.99)$ & $(-2.46)$ \\
\hline \multirow[t]{2}{*}{ Distance $\mathrm{x}$ Tracts in MSA (in 1,000s) } & & 0.0035 & 0.0016 & 0.0006 \\
\hline & & $(9.76)$ & $(4.68)$ & $(1.53)$ \\
\hline \multirow[t]{2}{*}{$\%$ Dwellings 0 to 4 years $^{a}$} & & & 0.5737 & 1.2131 \\
\hline & & & (24.33) & $(44.17)$ \\
\hline \multirow[t]{2}{*}{$\%$ Dwellings 5 to 9 years $^{a}$} & & & 0.8191 & 0.4133 \\
\hline & & & $(22.52)$ & $(12.83)$ \\
\hline \multirow[t]{2}{*}{$\%$ Dwellings 10 to 19 years $^{a}$} & & & 0.3525 & 0.7106 \\
\hline & & & $(15.55)$ & $(25.70)$ \\
\hline \multirow[t]{2}{*}{$\%$ Dwellings 20 to 29 years $^{a}$} & & & 0.0664 & 0.7114 \\
\hline & & & $(3.18)$ & $(20.25)$ \\
\hline \multirow[t]{2}{*}{$\%$ Dwellings 30 to 39 years $^{a}$} & & & -0.0127 & \\
\hline & & & $(-0.55)$ & \\
\hline \multirow[t]{2}{*}{$\%$ Dwellings 40 to 49 years $^{a}$} & & & 0.2888 & \\
\hline & & & $(13.48)$ & \\
\hline \multirow[t]{2}{*}{$\%$ Dwellings 40 or more years ${ }^{a}$} & & & & 0.3978 \\
\hline & & & & $(12.87)$ \\
\hline \multirow[t]{2}{*}{$\%$ Dwellings 60 or more years ${ }^{a}$} & & & -0.9094 & \\
\hline & & & $(-24.12)$ & \\
\hline \multirow[t]{2}{*}{ Constant } & 0.9772 & 0.98 & 0.9092 & 0.4053 \\
\hline & $(300.09)$ & $(299.31)$ & $(75.56)$ & $(16.58)$ \\
\hline Observations & 50,511 & 50,511 & 50,511 & 48,458 \\
\hline MSA Fixed Effecs & 331 & 331 & 331 & 325 \\
\hline R-Square & 0.0016 & 0.0035 & 0.1059 & 0.0970 \\
\hline RMSE & 0.4646 & 0.4642 & 0.4397 & 0.4376 \\
\hline
\end{tabular}

${ }^{a}$ Omitted category when using year 2000 (1980) dwelling ages is the percent of dwellings 50 to 59 (30 to 39) years or more in age. 
Table 2: Neighborhood Economic Status By MSA Size

(Dependent variable is Year 2000 census tract average income

relative to MSA average income; t-ratios in parentheses)

\begin{tabular}{|c|c|c|c|c|c|c|c|c|c|c|c|c|}
\hline & Fewe & $r$ Than 100 & Tracts & & to $500 \mathrm{Tr}$ & & 500 & to $1000 \mathrm{Tr}$ & acts & More & Than 1000 & Tracts \\
\hline & $\begin{array}{l}\text { Omit Age } \\
\text { Controls }\end{array}$ & $\begin{array}{c}\text { Year } 2000 \\
\text { Age } \\
\text { Controls }\end{array}$ & $\begin{array}{c}\text { Year } 1980 \\
\text { Age } \\
\text { Controls }\end{array}$ & $\begin{array}{l}\text { Omit Age } \\
\text { Controls }\end{array}$ & $\begin{array}{c}\text { Year } 2000 \\
\text { Age } \\
\text { Controls }\end{array}$ & $\begin{array}{c}\text { Year } 1980 \\
\text { Age } \\
\text { Controls }\end{array}$ & $\begin{array}{l}\text { Omit Age } \\
\text { Controls }\end{array}$ & $\begin{array}{c}\text { Year } 2000 \\
\text { Age } \\
\text { Controls } \\
\end{array}$ & $\begin{array}{c}\text { Year } 1980 \\
\text { Age } \\
\text { Controls }\end{array}$ & $\begin{array}{l}\text { Omit Age } \\
\text { Controls }\end{array}$ & $\begin{array}{c}\text { Year } 2000 \\
\text { Age } \\
\text { Controls }\end{array}$ & $\begin{array}{c}\text { Year } 1980 \\
\text { Age } \\
\text { Controls } \\
\end{array}$ \\
\hline Distance (Miles from city center) & 0.0014 & -0.0023 & 0.0003 & 0.0017 & -0.0019 & 0.0007 & -0.0001 & -0.0049 & -0.0019 & 0.0053 & -0.0008 & -0.0006 \\
\hline & $(3.41)$ & $(-5.92)$ & $(0.74)$ & $(5.74)$ & $(-6.48)$ & $(2.16)$ & $(-0.39)$ & $(-12.69)$ & $(-4.75)$ & $(9.13)$ & $(-1.28)$ & $(-0.86)$ \\
\hline$\%$ Dwellings 0 to 4 years $^{a}$ & & 0.5331 & 1.1740 & & 0.6077 & 1.2058 & & 0.6866 & 0.8693 & & 0.4192 & 1.4850 \\
\hline & & $(10.95)$ & $(20.64)$ & & $(18.50)$ & $(27.88)$ & & $(14.43)$ & $(13.73)$ & & $(4.78)$ & $(20.00)$ \\
\hline$\%$ Dwellings 5 to 9 years $^{a}$ & & 1.1426 & 0.3657 & & 0.9468 & 0.2456 & & 1.0781 & 0.2343 & & -0.2670 & 0.6943 \\
\hline & & $(15.17)$ & $(5.35)$ & & $(18.82)$ & $(4.90)$ & & $(15.07)$ & $(3.24)$ & & $(-2.06)$ & $(8.34)$ \\
\hline$\%$ Dwellings 10 to 19 years $^{a}$ & & 0.5080 & 0.7774 & & 0.3602 & 0.6791 & & 0.2921 & 0.3684 & & 0.5592 & 0.9110 \\
\hline & & $(10.62)$ & $(13.40)$ & & $(10.82)$ & $(15.55)$ & & $(6.54)$ & $(5.66)$ & & $(7.91)$ & $(14.52)$ \\
\hline$\%$ Dwellings 20 to 29 years $^{a}$ & & 0.2555 & 0.6168 & & 0.1097 & 0.6470 & & 0.1346 & 0.3725 & & -0.1366 & 0.9729 \\
\hline & & $(6.00)$ & $(7.97)$ & & $(3.55)$ & (11.35) & & $(3.17)$ & $(4.49)$ & & $(-2.21)$ & (12.97) \\
\hline$\%$ Dwellings 30 to 39 years $^{a}$ & & 0.2093 & & & 0.0389 & & & -0.0026 & & & -0.1829 & \\
\hline & & $(4.31)$ & & & $(1.10)$ & & & $(-0.01)$ & & & $(-3.09)$ & \\
\hline$\%$ Dwellings 40 to 49 years $^{a}$ & & 0.4747 & & & 0.3406 & & & 0.2167 & & & 0.1746 & \\
\hline & & $(9.88)$ & & & $(10.19)$ & & & $(4.67)$ & & & $(3.48)$ & \\
\hline$\%$ Dwellings 40 or more years ${ }^{a}$ & & & 0.2498 & & & 0.3289 & & & 0.1294 & & -1.3466 & 0.6682 \\
\hline & & & $(3.93)$ & & & $(6.58)$ & & & $(1.72)$ & & & $(10.06)$ \\
\hline$\%$ Dwellings 60 or more years ${ }^{a}$ & & -0.7062 & & & -0.7456 & & & -0.6071 & & & & \\
\hline & & $(-8.63)$ & & & $(-12.52)$ & & & $(-6.77)$ & & & $(-16.19)$ & \\
\hline Constant & 0.9877 & 0.7279 & 0.4427 & 0.9789 & 0.8345 & 0.4390 & 1.0023 & 0.8801 & 0.6603 & 0.9226 & 1.1333 & 0.2663 \\
\hline & $(199.88)$ & $(31.63)$ & $(8.65)$ & $(203.10)$ & $(44.99)$ & $(11.12)$ & $(134.22)$ & $(31.96)$ & $(11.02)$ & $(88.73)$ & $(38.82)$ & $(5.14)$ \\
\hline Observations & 10,223 & 10,223 & 9,816 & 20,004 & 20,004 & 19,274 & 10,669 & 10,669 & 10,279 & 9,615 & 9,615 & 9,089 \\
\hline MSA Fixed Effects & 217 & 217 & 211 & 91 & 91 & 91 & 17 & 17 & 17 & 6 & 6 & 6 \\
\hline R-Square & 0.0012 & 0.1632 & 0.1684 & 0.0017 & 0.1278 & 0.1126 & 0.0000 & 0.1139 & 0.0734 & 0.0086 & 0.0721 & 0.0799 \\
\hline RMSE & 0.3422 & 0.3133 & 0.3146 & 0.4378 & 0.4092 & 0.4127 & 0.4836 & 0.4554 & 0.4657 & 0.5893 & 0.5703 & 0.5495 \\
\hline
\end{tabular}

${ }^{a}$ Omitted category when using year 2000 (1980) dwelling ages is the percent of dwellings 50 to 59 (30 to 39) years or more in age. 


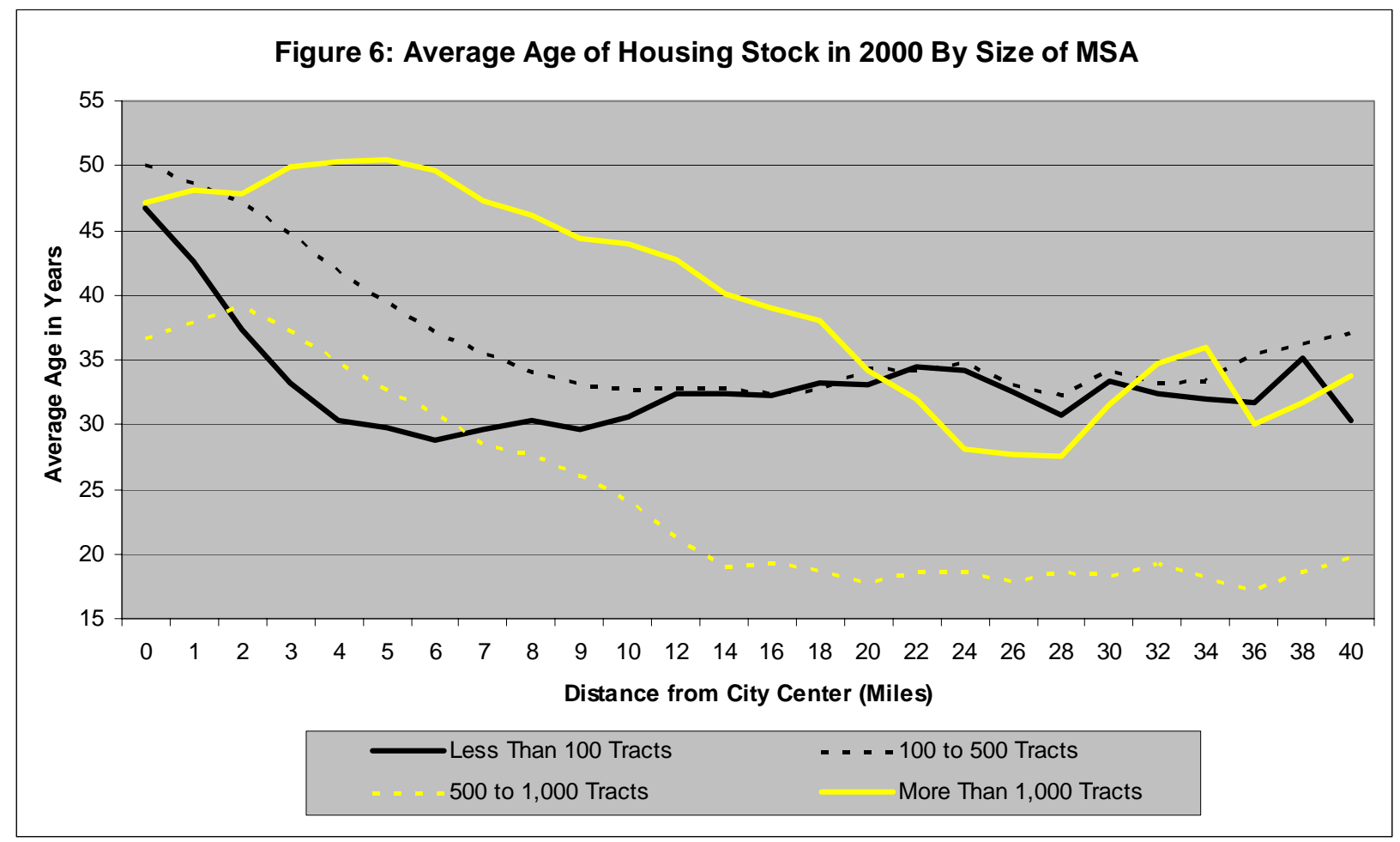



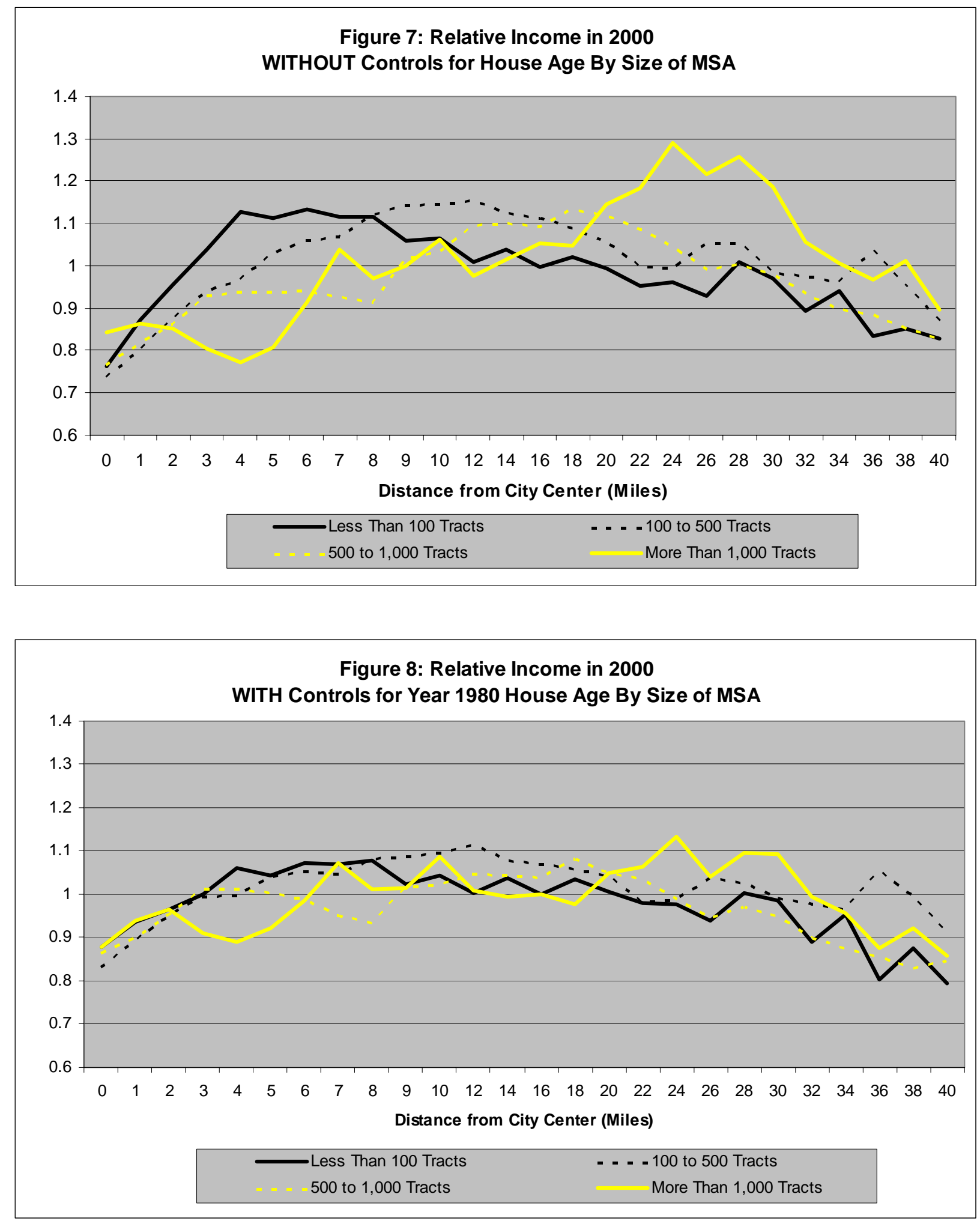

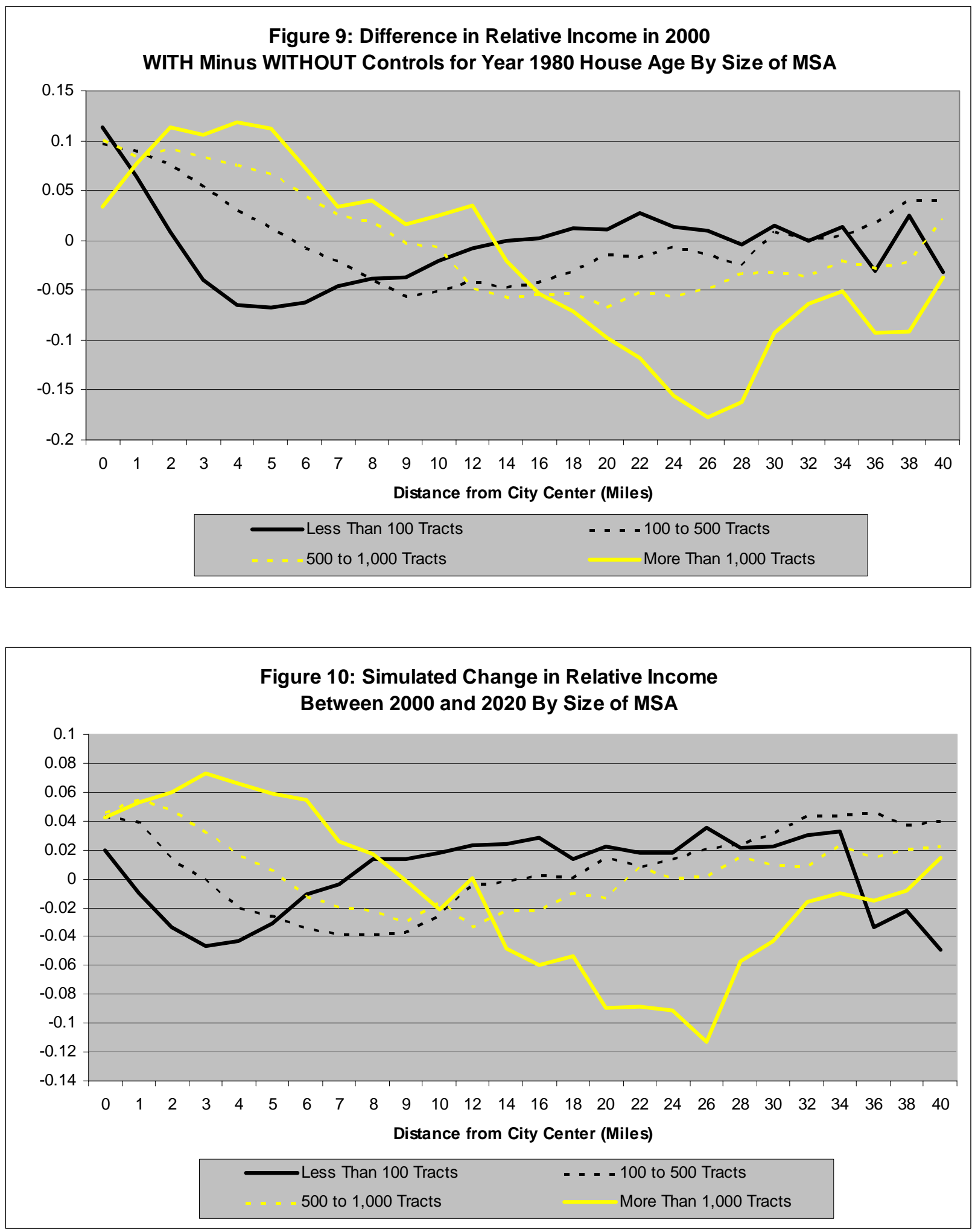


\section{Appendix A: Proofs and Additional Derivations}

\section{Proof of Proposition 2}

Suppose the city has two dwelling generations at time $\hat{t}$, and consider the location $\tilde{x}_{1}$ in the first-generation area where rich and poor bid rents are equal. The dwelling age at this location, denoted $\widetilde{a}_{1}$, is the first-generation critical age. Next, find the location, denoted $\breve{x}<\widetilde{x}_{1}$, in the second-generation area where age equals $\widetilde{a}_{1}$. Repeating the steps leading to (8) for the present case yields

$$
R_{r}(\breve{x})-R_{p}(\breve{x})=R_{r}\left(\tilde{x}_{1}\right)-R_{p}\left(\tilde{x}_{1}\right)+\left(\hat{y}_{r}-\hat{y}_{p}\right) \tau\left(\tilde{x}_{1}-\breve{x}\right)=\left(\hat{y}_{r}-\hat{y}_{p}\right) \tau\left(\tilde{x}_{1}-\breve{x}\right)>0,
$$

which shows that the rich outbid the poor for dwellings at $\breve{x}$. As a result, the location where second-generation bids are equal, denoted $\tilde{x}_{2}$, satisfies $\widetilde{x}_{2}<\breve{x}$, and the dwelling age $\widetilde{a}_{2}$ at that location (the second-generation critical age), satisfies $\tilde{a}_{2}>\tilde{a}_{1}$. The argument clearly generalizes to an arbitrary number of generations, establishing the Proposition.

\section{Derivation of $T(x)$ and simulation parameter values}

To make the analysis tractable, preferences over $c$ and age $a$ are assumed to be linear, with utility given by $c-\alpha_{r} a$ for the rich and $c-\alpha_{p} a$ for the poor. ${ }^{19}$ Let $u_{r}(t)$ and $u_{p}(t)$ denote the time paths of utility for the two groups. These time paths are assumed to be exogenous, reflecting the assumption of an open-city model. Then, age-conditional bid-rent functions for the two groups are given by $S_{r}(x, t, a)=y_{r}(t)(1-\tau x)-\alpha_{r} a-u_{r}(t)$ and $S_{p}(x, t, a)=y_{p}(t)(1-\tau x)-\alpha_{p} a$ $-u_{p}(t)$. The unconditional bid-rent function $R(x, t)$ comes from substituting $a(x, t)$, a function that is yet to be determined, into these age-conditional functions.

\footnotetext{
${ }^{19}$ Two aspects of this formulation deserve note. First, preferences are written directly in terms of age rather than housing services $h$. Second, preferences differ between the groups, with the age parameters $\alpha_{p}>0$ and $\alpha_{r}>\alpha_{p}$
} 
The next assumption is that income and utility increase linearly over time, with $t=0$ intercepts given by $\bar{y}_{r}, \bar{y}_{p}, \bar{u}_{r}$, and $\bar{u}_{p}$. Substituting into $S_{p}$ and $S_{r}$ above and setting the two bidrents equal yields the following expression for the critical age at location $x$ :

$$
\widetilde{a}(x)=\frac{\left(\bar{y}_{r}-\bar{y}_{p}\right)(1-\tau x)-\left(\bar{u}_{r}-\bar{u}_{p}\right)}{\alpha_{r}-\alpha_{p}} .
$$

Note that since the critical-age solution does not depend on $t$, the age at which a dwelling switches from rich to poor occupancy is independent of when it was built, depending only on location. $^{20}$ The critical age rises as $x$ falls, validating Proposition 2 for this special case.

Using the above information, the present value of revenue as of the construction date from a single dwelling built at time $t$ at location $x$ is given by

$$
\int_{0}^{\widetilde{a}(x)} S_{r}(x, a+t, a) e^{-\rho a} d a+\int_{\widetilde{a}(x)}^{L} S_{p}(x, a+t, a) e^{-\rho a} d a,
$$

where $\rho$ is the discount rate. Note in (A3) that calendar time is represeted by the construction date $t$ plus age $a$. Evaluating the integrals in (A3) using (A2) and the bid-rent formulas yields an expression equal to $g(x)+f(x) t$, where $g$ and $f$ are complicated functions, with $f>0 .{ }^{21}$

For land first developed at time $T$, subsequent redevelopment dates are given by $t=T+$ $i L$, for $i=1,2,3, \ldots$ Using (A3), the present value of revenue as of date $T$ from the entire sequence of dwellings is then given by

different for the rich and poor. This setup thus overturns the common-preference assumption in the general model above, but it does generate the key income-related difference in MRS's that appears in (3) and (4).

${ }^{20}$ The reason is that the linear income and utility time trends cancel in the calculation.

${ }^{21}$ The function $f(x)$ is given by $[\beta(1-\tau x)-\gamma]\left(1-e^{-\rho L}\right) / \rho$, where $\beta$ and $\gamma$ are the income and utility time trends respectively. It is assumed that $\beta(1-\tau x)-\gamma>0$ holds over the relevant range of $x$ values so that $f$ is positive. In addition,

$$
\begin{aligned}
g(x)= & {\left.\left.[1-\tau x) \bar{y}_{r}-\bar{u}_{r}\right]\left(1-e^{-\rho \tilde{a}(x)}\right) / \rho+[1-\tau x) \bar{y}_{p}-\bar{u}_{p}\right]\left(e^{-\rho \tilde{a}(x)}-e^{-\rho L}\right) / \rho-\alpha_{r}\left[1-e^{-\rho \tilde{a}(x)}-\rho \tilde{a}(x) e^{-\rho \tilde{u}(x)}\right] / \rho^{2} } \\
& -\alpha_{p}\left[\rho \tilde{a}(x) e^{-\rho \tilde{a}(x)}-\rho L e^{-\rho L}+e^{-\rho \tilde{a}(x)}-e^{-\rho L}\right] / \rho^{2}+[\beta(1-\tau x)]\left(1-e^{-\rho L}-\rho L e^{-\rho L}\right) / \rho^{2}
\end{aligned}
$$




$$
\left.\sum_{i=0}^{\infty}[g(x)+f(x)(T+i L)]\right]^{-\rho i L}
$$

To avoid inessential complexity, it is assumed that a unit of land accommodates exactly one dwelling regardless of location (yielding constant density) and that construction costs are zero, so that (A4) directly gives the present value of profit per unit of land. Then, the development date $T(x)$ for land at location $x$ is found by setting (A4) equal to agricultural land value, $V_{a}$, which is assumed to be constant over time, and solving for $T$. Since (A4) is increasing in $T$ and decreasing in $x$, it follows that $T^{\prime}(x)>0 .{ }^{22}$

The simulation results in the Figures use the following parameter values: $L=75, \rho=.05$, $\tau=.004, \bar{y}_{r}=100, \bar{y}_{p}=70, \bar{u}_{r}=50, \bar{u}_{p}=30, \alpha_{\mathrm{r}}=1.3, \alpha_{\mathrm{p}}=1.0, \beta=.04, \gamma=.03$ (the latter parameters are the income and utility time trends). $V_{a}$ is set at 966.5 , a value that yields $T(0)=0$, so that the city starts as a point at time zero. It should be noted that, while the $T(x)$ function emerging from these calculations appears to be linear (see Figure 1), this linearity is only approximate, as can be seen by working through the calculations described above.

As usual in an open-city model, the exogenous utility paths generate endogenous time paths for the populations of both groups, which are not presented here. Note, however, that the simulation can also be viewed as portraying a closed city whose population evolves exogenously along the given paths, with the now-endogenous utility paths equal, by construction, to the ones specified in the simulation.

\footnotetext{
${ }^{22}$ The fact that (A4) is decreasing in $x$ can be seen by differentiating (A3) and recalling that the functions $S_{r}$ and $S_{p}$ are decreasing in $x$.
} 


\section{Appendix B: Alternative Controls for the Age Distribution of the Housing Stock in Comparison to Figure 9}
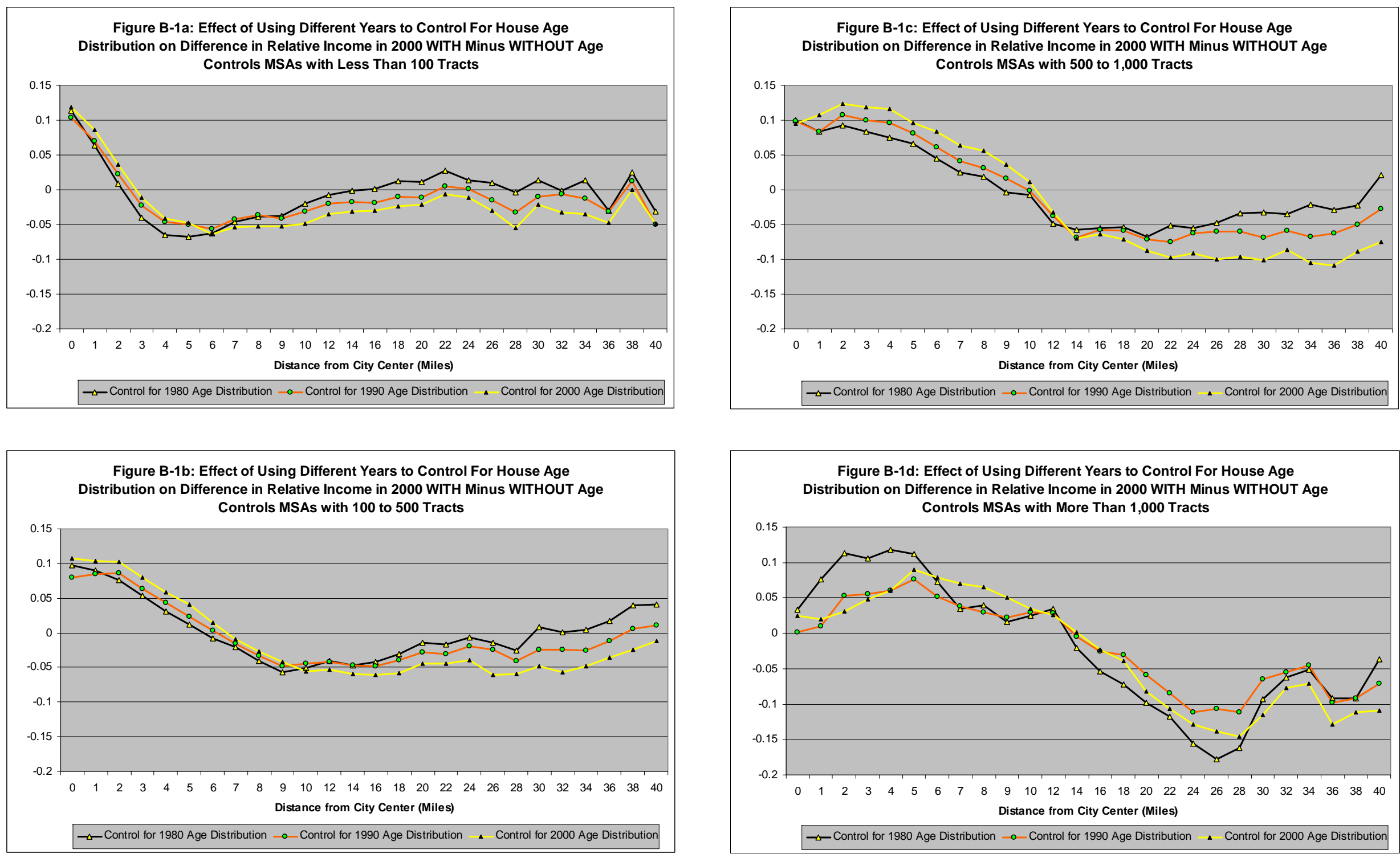